Review

\title{
Strategies for Improving the Sensing Performance of Semiconductor Gas Sensors for High-Performance Formaldehyde Detection: A Review
}

\author{
Zhenyu Yuan (i), Chang Yang and Fanli Meng *(i) \\ College of Information Science and Engineering, Northeastern University, Shenyang 110819, China; \\ yuanzhenyu@ise.neu.edu.cn (Z.Y.); 2070835@stu.neu.edu.cn (C.Y.) \\ * Correspondence: mengfanli@ise.neu.edu.cn
}

Citation: Yuan, Z.; Yang, C.; Meng, F. Strategies for Improving the Sensing Performance of Semiconductor Gas Sensors for High-Performance Formaldehyde Detection: A Review. Chemosensors 2021, 9, 179.

https://doi.org/10.3390/

chemosensors 9070179

Academic Editor: Simonetta Capone

Received: 31 May 2021

Accepted: 9 July 2021

Published: 14 July 2021

Publisher's Note: MDPI stays neutral with regard to jurisdictional claims in published maps and institutional affiliations.

Copyright: (c) 2021 by the authors. Licensee MDPI, Basel, Switzerland. This article is an open access article distributed under the terms and conditions of the Creative Commons Attribution (CC BY) license (https:// creativecommons.org/licenses/by/ $4.0 /)$.

\begin{abstract}
Formaldehyde is a poisonous and harmful gas, which is ubiquitous in our daily life. Longterm exposure to formaldehyde harms human body functions; therefore, it is urgent to fabricate sensors for the real-time monitoring of formaldehyde concentrations. Metal oxide semiconductor (MOS) gas sensors is favored by researchers as a result of their low cost, simple operation and portability. In this paper, the mechanism of formaldehyde detection by gas sensors is introduced, and then the ways of ameliorating the response of gas sensors for formaldehyde detection in recent years are summarized. These methods include the control of the microstructure and morphology of sensing materials, the doping modification of matrix materials, the development of new semiconductor sensing materials, the outfield control strategy and the construction of the filter membrane. These five methods will provide a good prerequisite for the preparation of better performing formaldehyde gas sensors.
\end{abstract}

Keywords: formaldehyde detection; metal oxide semiconductor; noble metal; heterojunction; gas sensing mechanism

\section{Introduction}

Formaldehyde is a transparent toxic gas with a pungent odor; the World Health Organization (WHO) stipulates that the indoor formaldehyde content should not be higher than $0.08 \mathrm{ppm}$. Once it exceeds the limit value, it will damage people's health within a certain period of time [1]. Formaldehyde exists in a wide range of fields, such as in interior decoration where it is commonly used in plating, paints, carpets, and wallpaper; preservatives and disinfectants used in medicine; even in the textile industry, formaldehyde is added to solvents as an aid for wrinkle resistance, shrinkage prevention and durability of printing and dyeing [2]. The main forms of human exposure to formaldehyde are inhalation through the respiratory tract and contact through the skin. When the concentration of formaldehyde reaches a certain level, it may cause respiratory tract inflammation and skin inflammation, or cause gastrointestinal and systemic poisoning symptoms [3,4]. Therefore, the detection of formaldehyde cannot be neglected. At present, the detection methods of formaldehyde include spectrophotometry [5-7], gas chromatography [8], electrochemical methods $[9,10]$, and semiconductor gas sensors. Compared with semiconductor gas sensors, the above detection methods have a large equipment size and are costly and complex to operate, so semiconductor gas sensors have attracted extensive attention of researchers.

In addition to semiconductor gas sensors, there are also electrochemical, optical, solid electrolyte, quartz crystal microbalance (QCM) gas sensor, etc. depending on the detection principle. Electrochemical gas sensors are designed and prepared based on the redox processes at the electrode, which have the advantages of good repeatability and high resolution. However, they are vulnerable to interference and have a high cost and poor stability. Optical sensors depend on the optical characteristics of the gases and have 
high-precision, but are vulnerable to dust and are expensive [11]. Solid electrolyte gas sensor detects gas by the interaction between the test gas and the solid substances with ion conductivity characteristics, high sensitivity and good selectivity with an insufficient lifespan [12]. The quartz crystal microbalance (QCM) gas sensor uses the frequency change caused by the mass change on the quartz crystal oscillator to realize gas concentration detection. This type of sensor can detect and predict the sensitive material of the target gas at room temperature, but it is difficult to meet the needs of miniaturization [13]. Semiconductor gas sensors are designed based on the principle that the adsorption between semiconductor materials and gas molecules causes the electrical characteristics to change. Although the characteristics such as the short linear range and susceptibility to interference need to be improved, it has advantages such as fast response, low cost, simple structure, long life, miniaturization, easy operation, which make it become one of the research hotpots.

At present, the most widely studied gas sensor is the semiconductor gas sensor with metal oxide as the gas-sensing material. The metal oxide semiconductor (MOS) stands out due to its high sensitivity, low cost and quick response speed [14]. The most commonly used metal oxides are $\mathrm{SnO}_{2}$ [15], $\mathrm{ZnO}$ [16], $\mathrm{In}_{2} \mathrm{O}_{3}$ [17], $\mathrm{WO}_{3}$ [18], $\mathrm{NiO}$ [19] and $\mathrm{Co}_{3} \mathrm{O}_{4}$ [20]; the study found that they are valuable oxides for monitoring formaldehyde. However, there are still some defects such as long response time, poor specificity and high energy consumption.

For semiconductor gas sensors, the interaction between gas and sensitive materials usually includes carrier transfer, adsorption and surface reaction [21,22]. The gas-sensing mechanism is mainly explained by constructing two models: the space charge layer model and the grain boundary barrier model.

a. The space charge model

The detection mechanism of formaldehyde is as follows: Firstly, the oxygen in the air acquires electrons from the sensitive material and becomes adsorbed oxygen, including $\mathrm{O}_{2}{ }^{-}, \mathrm{O}^{-}$and $\mathrm{O}^{2-}$, at different temperatures, the oxygen ions formed are different, as shown in Equations (1)-(3) [23].

$$
\begin{gathered}
\mathrm{O}_{2} \text { (ads) }+\mathrm{e}^{-} \rightarrow \mathrm{O}_{2}^{-} \text {(ads) } \mathrm{T}<147^{\circ} \mathrm{C} \\
\mathrm{O}_{2}^{-} \text {(ads) }+\mathrm{e}^{-} \rightarrow 2 \mathrm{O}^{-} \text {(ads) } \quad 147{ }^{\circ} \mathrm{C}<\mathrm{T}<397^{\circ} \mathrm{C} \\
\mathrm{O}^{-} \text {(ads) }+\mathrm{e}^{-} \rightarrow \mathrm{O}^{2-} \text { (ads) } \quad \mathrm{T}>397^{\circ} \mathrm{C}
\end{gathered}
$$

Take the n-type semiconductor as an example. After losing electrons, the energy band of the n-type semiconductor bends upward and forms a carrier depletion zone, making the carrier concentration lower. When encountering formaldehyde gas, it will undergo a redox reaction with adsorbed oxygen, as shown in Equation (4) [24], the seized electrons will then return to the sensitive material, and the carrier depletion zone becomes narrower, thus changing the conductivity.

$$
\mathrm{HCHO}+\mathrm{O}^{-} \text {(ads) } \rightarrow \mathrm{CO}_{2}+\mathrm{H}_{2} \mathrm{O}+\mathrm{e}^{-}
$$

b. The grain boundary barrier model

There are several crystal particles and grain boundaries in oxide semiconductors. In the n-type sensitive material in contact with air, the electrons in the material are acquired by oxygen, forming a high-resistance area at the grain boundary, forming a grain boundary barrier, which will affect the transport of carriers. When encountering formaldehyde gas, oxygen ions and reducing gas undergo a chemical reaction, the trapped electrons reenter the sensitive material, and the barrier height decreases, the electrons are easy to transport, and conductivity increases.

In the two models, gas diffusion, absorption and desorption are the main factors affecting gas-sensing parameters, which are related to the structure of the gas-sensing material, including porosity, film thickness and grain size, etc. The higher the porosity, 
the thinner the film thickness, which is more conducive to gas diffusion and electron transmission, thereby shortening the response time.

Professor N. Yamazoe [25] proposed three factors that affect the performance of oxide semiconductor gas sensor, including recognition function, conversion function and the utilization ratio of the sensitive body. The recognition function refers to the ability of sensitive materials to identify gas molecules. The acid-base attribute [26], redox characteristics and construction of the sensitive materials have great impact on it [27]. The conversion function refers to the ability of sensitive materials to convert the concentration signal of the gas to resistance signal, depending on parameters such as grain size [28,29], crystallinity and the mobility of the carrier of the sensitive materials [30]. The utilization ratio of the sensitive body refers to the proportion of the sensitive body to the whole sensitive body in the change of resistance in the gas to be measured, which is usually affected by the porosity and the dispersion of the sensitive material [31].

Under the guidance of the above sensing theory, researchers have carried out a tremendous amount of research on improving the performance of oxide semiconductor gas sensors. In this paper, the methods of improving the gas response of sensors for highperformance formaldehyde detection in recent years are reviewed, including the control of microstructures and the morphology of sensitive materials, the doping modification of matrix materials, the application of new materials, outfield control and the construction of the filter membrane, the final part of this paper briefly introduces the impact of device structure on sensor performance.

\section{Control the Microstructure and Morphology of Sensitive Materials}

The gas-sensing response is positively correlated with the quantity of adsorbed gas, and the morphology and surface state of the sensing material largely determines the quantity of adsorbed gas [32]. Consequently, the response value is seriously influenced by the surface state of the sensitive material. Research on sensitive materials has gradually developed from irregular powder materials in the beginning to micro-nano materials at the present stage, such as various 0-dimensional (nanoparticles [33,34], quantum dots [35]), 1-dimensional (nanowires [36], nanofibers), 2-dimensional (nanosheets [37]) and 3-dimensional (flower-like [38,39], spherical [40]) nanostructured materials. Due to the unique properties of its nanometer size, nanomaterials have a sharp edge in the field of gas sensing. The response of formaldehyde to morphological modification is displayed in Table 1 and discussed in the following section. The response parameter in the table represents the sensitivity to a particular concentration of detection gas. The sensitivity to formaldehyde can be expressed as $S=R_{a} / R_{g}$ (n-type semiconductor) or $S=R_{g} / R_{a}$ (p-type semiconductor). $R_{a}$ and $R_{g}$ represent the resistance of the sensor in air and the detection gas, respectively.

\section{1. $1 D$ Nanostructures}

For oxide semiconductors, a low dimensional structure leads to an electronic limiting effect, which results in the limitation of carrier motion direction [41]. For one-dimensional nanowire, the carrier only moves along the axial direction, resulting in a significant increase in mobility. Xu et al. [42] successfully prepared hierarchical porous- $\mathrm{SnO}_{2}$ nanorods (HP$\mathrm{SnO}_{2}$ ) assembled by nanoparticles by introducing the topological transformation (TTF) method on the surface of the coplanar sensor and combining traditional screen printing and calcination. Figure 1 is the SEM pattern of $\mathrm{HP}-\mathrm{SnO}_{2}$ microrods. The gas-sensing tests indicate that the $\mathrm{HP}-\mathrm{SnO}_{2}$ sensor not only has a fast response speed but also has high sensitivity. 


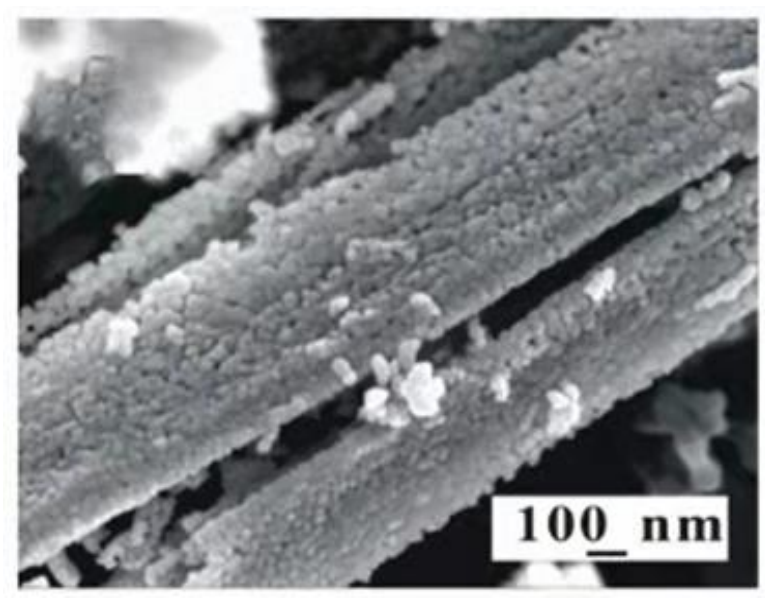

Figure 1. SEM images of thick film based on L-HP-SnO $\mathrm{S}_{2}$ microrods [42].

Tian et al. [31] successfully prepared graded mesoporous $\mathrm{SnO}_{2}$ nanofibers with different micro structure. By changing the calcination temperature, the effect of calcination temperature on the grain growth was studied. The results show that the appropriate aperture and large effective surface area have a great influence on the performance improvement. Zhao's team. [43] prepared Co-doped $\mathrm{SnO}_{2}$ nanofibers (NFs) with a one-dimensional structure using the simple hydrothermal route and annealing treatment using Shaddock Peel's biological template; the results of the morphology and gas sensitivity test are shown in Figure 2. The sensor with the optimum doping content of $5 \%$ has a unique selectivity to formaldehyde. In particular, at the lowest detection concentration of $1 \mathrm{ppm}$, the response can reach 4.05. Its excellent performance comes from the unique one-dimensional structure and the catalytic effect of $\mathrm{Cd}$.

\subsection{D Nanostructures}

Two-dimensional nanomaterials have a larger surface area, so they can absorb more gases, and the porosity of the material surface is conducive to the promotion of gas penetration, thereby improving the utilization of the sensing membrane, and ultimately improving gas sensitivity [44]. However, the fabrication of porous two-dimensional nanostructures remains a challenge.

Chen et al. [45] synthesized $\mathrm{ZnO}$ nanoplates with high porosity by an anion-mediated strategy and the one-step hydrothermal method. The synthesis process and the structural representations of the material are shown in Figure 3. The unique two-dimensional porous structure makes the sensor based on $\mathrm{ZnO}$ nanoplate have a lower detection limit and reliable selectivity to formaldehyde vapor. Zhang et al. [37] prepared $\mathrm{CeO}_{2}$ nanosheets that respond relatively quickly to $200 \mathrm{ppm} \mathrm{HCHO}$ at $300{ }^{\circ} \mathrm{C}$. The excellent sensing performance of ultrathin $\mathrm{CeO}_{2}$ nanosheets is ascribed to their geometric sensitization. Using $\mathrm{GO}$ as template and sensitizer, in situ modified mesoporous ultrathin $\mathrm{SnO}_{2}$ nanosheets $\left(\mathrm{SnO}_{2}\right.$ NS) were successfully synthesized by Wang [46]. The experiment proved that mesoporous $\mathrm{GO} / \mathrm{SnO}_{2} \mathrm{NS}-475$ possessed superior specificity and an ultra-high response value at temperatures as low as $60^{\circ} \mathrm{C}$. Its unique ultrathin nanostructure and abundant mesopores are the key factors in improving the gas sensitive parameter. 


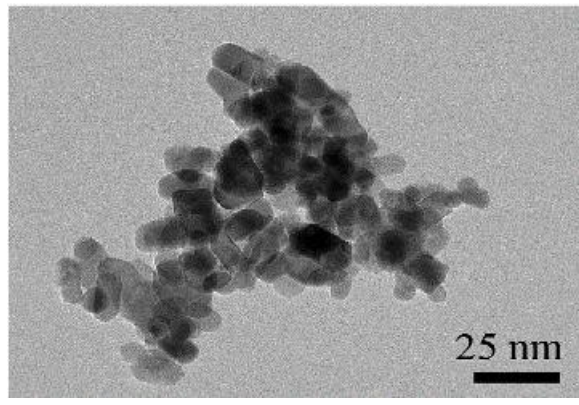

(a)

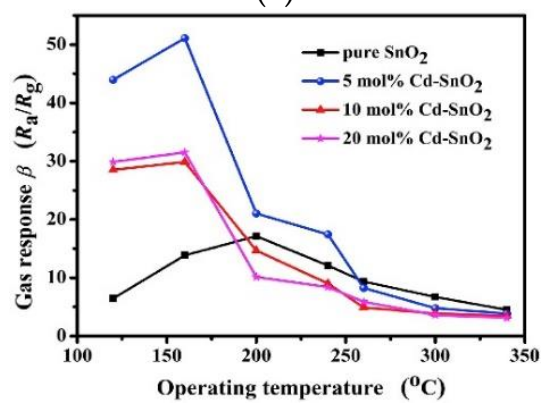

(d)

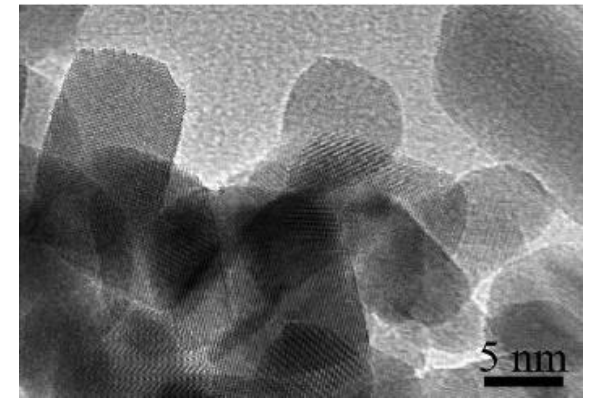

(b)

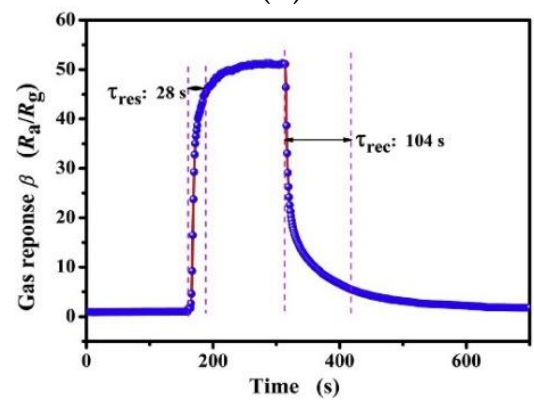

(e)

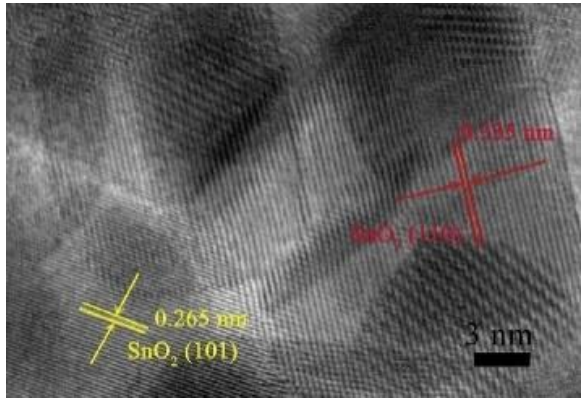

(c)

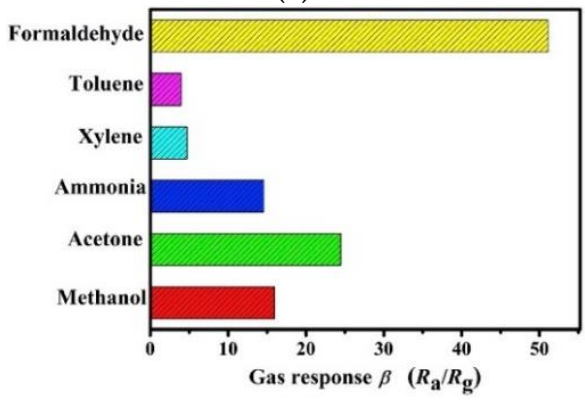

(f)

Figure 2. (a) TEM image and (b,c) HRTEM images of $5 \mathrm{~mol} \% \mathrm{Cd}$-doped $\mathrm{SnO}_{2}$ nanofibers prepared by shaddock peels as bio-templates; (d) gas responses of the sensors based on different $\mathrm{Cd}$-doped $\mathrm{SnO}_{2}$ nanofibers toward 100 ppm formaldehyde at various operating temperature; (e) response-recovery curve of the sensor towards 100 ppm formaldehyde at the operating temperature of $160^{\circ} \mathrm{C}$; (f) gas responses of the $5 \mathrm{~mol} \% \mathrm{Cd}$-doped $\mathrm{SnO}_{2}$ nanofibers based sensor towards $100 \mathrm{ppm}$ different volatile organic compounds gases at $160^{\circ} \mathrm{C}$ [43].

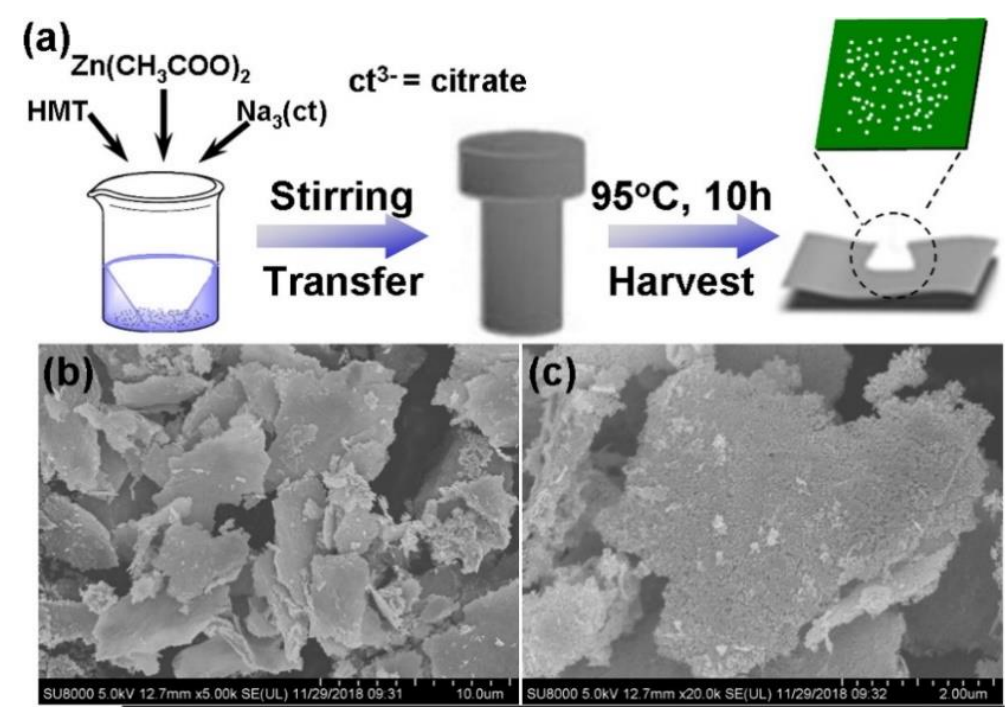

Figure 3. Schematic diagram for the synthesis (a); SEM images $(\mathbf{b}, \mathbf{c})[45]$.

\subsection{D Nanostructures}

Three-dimensional materials are favored by researchers because of their regular geometry, abundant pores and large specific surface area [47]. The core-shell structure, hierarchical structure and hollow structure are the main research hotspots at present.

Park et al. [48] prepared an $\alpha-\mathrm{Fe}_{2} \mathrm{O}_{3}$ microcube as a p-type semiconductor. When the detection concentration was $50 \mathrm{ppb}$, the response to formaldehyde was 5.2, and it had good long-term stability ( 210 days) at $300{ }^{\circ} \mathrm{C}$. Hu et al. [49] successfully prepared a $\mathrm{SnO}_{2}$ nanoflower-like structure by the simple hydrothermal method; the response was 34.6 to 100 ppm HCHO. Compared with other interfering gases of the same concentration, this 
response value is higher and the selectivity is better. Tao et al. [50] synthesized urchin-like $\mathrm{In}_{2} \mathrm{O}_{3}$ hollow microspheres HSs by template-free solvothermal synthesis. The sensor made from $\mathrm{In}_{2} \mathrm{O}_{3}-350$ had the characteristics of high response, superior specificity and short response time. The corresponding test results are shown in Figure 4. Its excellent sensing performance is the result of the rare urchin-like structure, abundant active sites and the appropriate particle size.

(a)

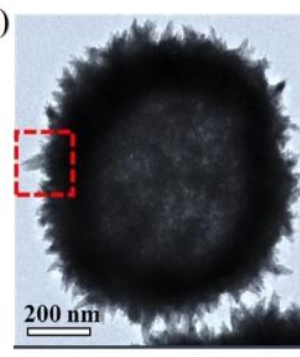

(b)

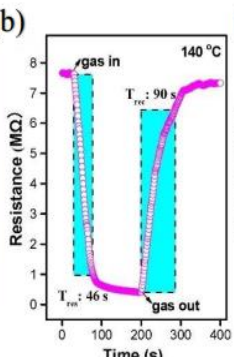

(c)

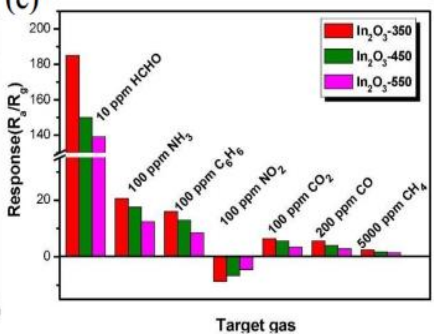

Figure 4. (a) TEM images of $\operatorname{In}_{2} \mathrm{O}_{3}-350$; (b) response transient of the $\operatorname{In}_{2} \mathrm{O}_{3}-350$ sensor to 1 ppm of $\mathrm{HCHO}$; (c) the response values of the $\mathrm{In}_{2} \mathrm{O}_{3}-350$ sensor to different gases at $140{ }^{\circ} \mathrm{C}$ [50].

Zi et al. [51] synthesized nano-plate coated microspheres, synthesis process as shown in Figure 5. The experimental results show that the CuO-5-based gas sensor has high specificity to formaldehyde. The reason for the improved sensitivity of the CuO-5-based sensors can be attributed to the special exposure crystal plane and active center. Zhang et al. [52] synthesized a cuprous oxide multi-shell structure by simply adjusting the cetyltrimethylammonium bromide (CTAB) concentration. At $120^{\circ} \mathrm{C}, \mathrm{Cu}_{2} \mathrm{O}$ spheres with four shells had a higher response (9.1) and a shorter response/recovery time $(5 \mathrm{~s} / 3 \mathrm{~s})$ than those with single, double and triple shells.

\section{a}
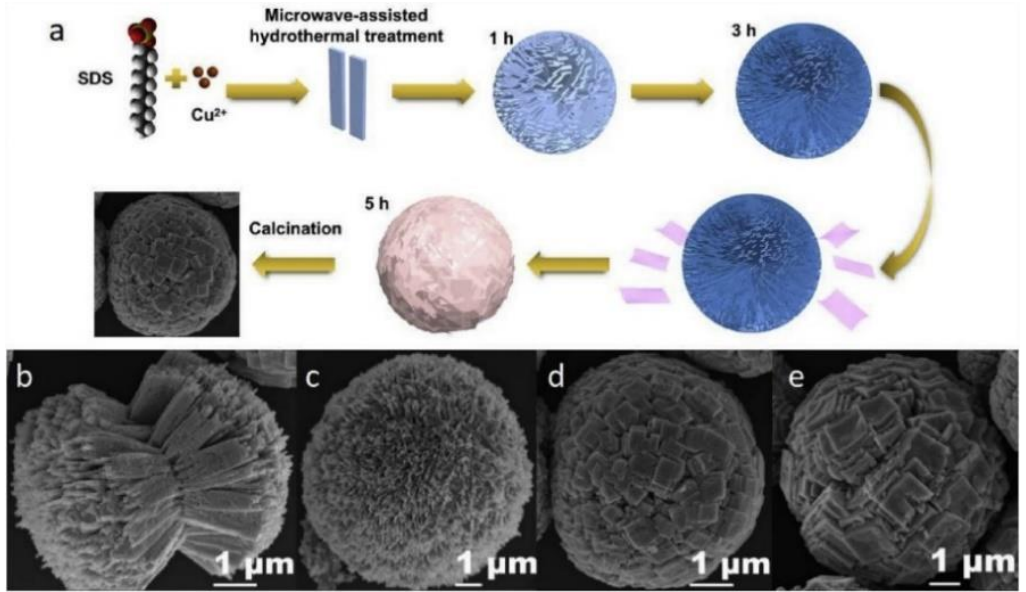

Figure 5. (a) Diagrammatic sketch of the plausible formation progress of the porous copper oxide microsphere. SEM images of the obtained samples with different reaction time: (b) $1 \mathrm{~h}$, (c) $3 \mathrm{~h}$, (d) $5 \mathrm{~h}$, and (e) $7 \mathrm{~h}$, respectively [51]. 
Table 1. Formaldehyde sensing properties of different gas-sensing materials.

\begin{tabular}{|c|c|c|c|c|c|}
\hline Materials & O.T. $\left({ }^{\circ} \mathrm{C}\right)$ & Conc. & Response & D.L. & Refs \\
\hline $\mathrm{HP}-\mathrm{SnO}_{2}$ nanorods & 330 & 100 ppm & 59.7 & $1 \mathrm{ppm}$ & [42] \\
\hline $\mathrm{SnO}_{2}$ nanofibers & 150 & $500 \mathrm{ppb}$ & 14.6 & $50 \mathrm{ppb}$ & [31] \\
\hline $5 \mathrm{~mol} \% \mathrm{Cd}$-doped $\mathrm{SnO}_{2} \mathrm{NFs}$ & 160 & 100 ppm & 51.1 & $1 \mathrm{ppm}$ & [43] \\
\hline $\mathrm{ZnO}$ nanoplates & 250 & 100 ppm & 16.8 & $1 \mathrm{ppm}$ & [45] \\
\hline ultra-thin $\mathrm{CeO}_{2}$ nanosheets & 300 & 200 ppm & 30 & 5 ppm & [37] \\
\hline $\mathrm{GO} / \mathrm{SnO}_{2} \mathrm{NS}$ & 60 & $100 \mathrm{ppm}$ & 2275.7 & - & [46] \\
\hline$\alpha-\mathrm{Fe}_{2} \mathrm{O}_{3}$ microcube & 300 & $1 \mathrm{ppm}$ & 5.2 & $50 \mathrm{ppb}$ & [48] \\
\hline $\mathrm{SnO}_{2}$ nanoflower & 300 & 100 ppm & 34.6 & 5 ppm & [49] \\
\hline Urchin-like $\operatorname{In}_{2} \mathrm{O}_{3}$ hollow spheres & 140 & $1 \mathrm{ppm}$ & 20.9 & $0.05 \mathrm{ppm}$ & {$[50]$} \\
\hline $\mathrm{CuO}$ microspheres & 30 & 80 ppm & 32 & - & [51] \\
\hline Multishell $\mathrm{Cu}_{2} \mathrm{O}$ microspheres & 120 & 200 ppm & 9.6 & $0.29 \mathrm{ppm}$ & [52] \\
\hline
\end{tabular}

O.T.: optimal temperature; D.L.: detection limit.

\section{Doping Modification of Matrix Materials}

The most direct and efficacious way to raise the gas-sensing characteristics of sensitive materials is to dope or modify the pure phase sensitive materials. The ability of original oxides to adsorb gas and catalyze reaction is limited, so achieving high gas sensitivity is very challenging. Currently, the functional modification of oxide semiconductors mainly includes metal cation doping, noble metal surface loading and semiconductor oxide composite, etc. [53]. (see Table 2 below for details).

\subsection{Metal Cation Doping}

Metal cations are introduced into the lattice of metal oxide semiconductors by using metal cations as donors or acceptors [54]. By controlling the type and amount of metal ions doping [55], the defect concentration, carrier concentration and the number of surface suspended bonds of the original sensitive materials are changed, Then, the adsorption and reaction features of gas numerators are promoted.

Wang et al. [56] prepared homogeneous and monodisperse Co-doped $\mathrm{In}_{2} \mathrm{O}_{3}$ nanorods, and pure $\mathrm{In}_{2} \mathrm{O}_{3}$ was also prepared under the same experimental conditions as the control experiment, the influence of $\mathrm{Co}$ ion doping was revealed. As depicted in Figure 6, the response of $1 \% \mathrm{Co} / \mathrm{In}_{2} \mathrm{O}_{3}$ sensor to $10 \mathrm{ppm} \mathrm{HCHO}$ at $130{ }^{\circ} \mathrm{C}$ was 23.2 , and the minimum monitoring concentration was $1 \mathrm{ppm}$. Zhu et al. [57] obtained Y-doped $\mathrm{SnO}_{2}$ hierarchical flowerlike nanostructures as shown in Figure 7a. The particularly excellent sensing performance is shown in Figure $7 \mathrm{~b}$,c. As $\mathrm{Y}$ ions were doped into the $\mathrm{SnO}_{2}$ lattice, more lattice defects were produced, which is helpful for absorbing more oxygen.
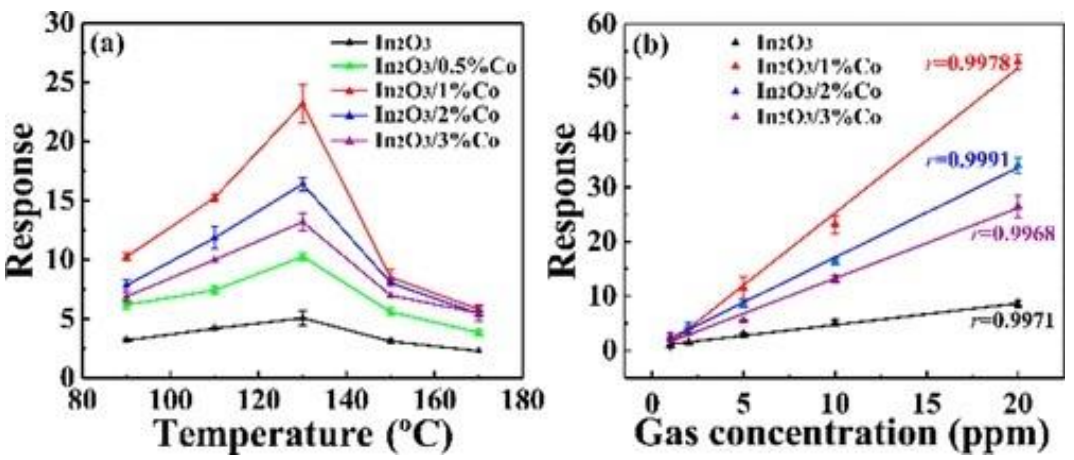

Figure 6. (a) Responses at various working temperature; (b) responses toward different $\mathrm{HCHO}$ concentrations [56]. 


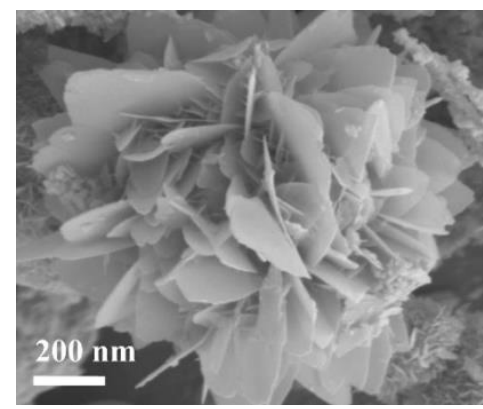

(a)

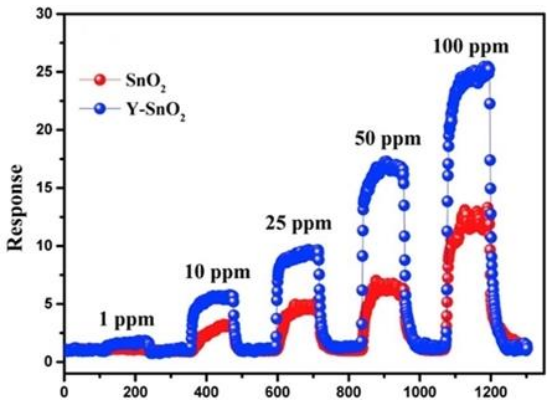

(b)

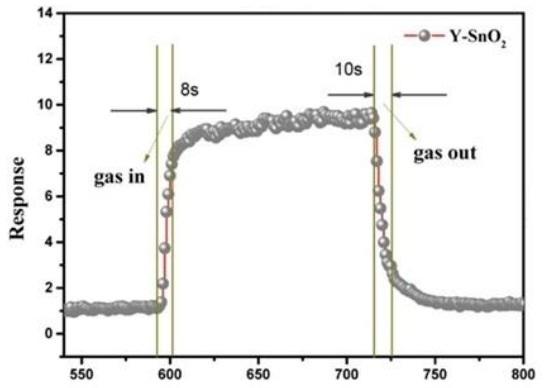

(c)

Figure 7. (a) SEM images of Y-doped $\mathrm{SnO}_{2}$; (b) the response/recovery curves to 1-100 ppm HCHO; (c) the dynamic sensing transient to 25 ppm $\mathrm{HCHO}$ of $\mathrm{SnO}_{2}$ and $\mathrm{Y}$-doped $\mathrm{SnO}_{2}$ [57].

Zhang et al. [58] synthesized Bi-doped $\mathrm{Zn}_{2} \mathrm{SnO}_{4} / \mathrm{SnO}_{2}$ nanospheres with a porous structure by hydrothermal reaction. The Bi-doped sensor had a high response of 23.2 to 50 ppm formaldehyde at $180^{\circ} \mathrm{C}$, and had good selectivity. K. Khojier. [59] prepared pure and $\mathrm{Al}$-doped $\mathrm{ZnO}$ thin films and studied them as formaldehyde sensors. The results show that the optimum doping amount of the $\mathrm{Al}$ atom in the $\mathrm{ZnO}$ matrix was $2 \mathrm{at} \%$. At $320{ }^{\circ} \mathrm{C}$, the sensitivity of $2 \mathrm{at} \% \mathrm{Al}$-doped $\mathrm{ZnO}$ to $\mathrm{HCHO}$ was the highest, and the detection limit was 0.5 ppm.

\subsection{Noble Metal Surface Loading}

Noble metals (such as $\mathrm{Pb}, \mathrm{Pt}, \mathrm{Au}, \mathrm{Ag}$ ) possess strong catalytic properties [60]. When the catalyst is introduced, most catalysts can seize electrons from sensitive materials as acceptors and form a great quantity of adsorbed oxygen. By trapping and releasing electrons in air and the target gas, the electron depletion region changes significantly, making the resistance drop significantly, thus improving the characteristics of gas sensitive materials, this sensitization mechanism is called electronic sensitization [61]. In addition to electronic sensitization, another sensitization mechanism is called chemical sensitization. Chemical sensitization comes from the surface catalytic reaction of catalyst. First, the catalyst promotes the adsorption and activation of the detection gas; then, the gas, after activation and cracking, spreads to the sensitive materials and rapidly interacts with the active oxygen. This process is also known as the spillover effect [62]. The catalyst plays a crucial role in promoting redox reaction, which effectively improves the gas recognition ability of sensitive substances [63].

Dong et al. [64] synthesized pure and Pt-loaded NiO hierarchical porous structures. Compared with the original $\mathrm{NiO}, \mathrm{Pt}$ nanoparticles affect the growth of $\mathrm{NiO}$ to some extent. Furthermore, the response to formaldehyde is enhanced clearly, especially the $\mathrm{NiO}$ with a load of $1 \%$ of $\mathrm{Pt}$ as shown in Figure 8. Xue et al. [65] prepared mesoporous $\mathrm{Ag} / \mathrm{In}_{2} \mathrm{O}_{3}$ composites by calcining Ag in an organic framework (OFs). The experimental results prove that when the load of $\mathrm{Ag}$ was $5 \%$, the response value of $\mathrm{Ag} / \mathrm{In}_{2} \mathrm{O}_{3}$ sensor was five times of that of the single oxide sensor under $210^{\circ} \mathrm{C}$. Gu et al. [66] obtained a high performance $\mathrm{HCHO}$ sensor on the nano-scale of $\mathrm{In}_{2} \mathrm{O}_{3}$ based on atom dispersion by UVassisted reduction. The response to $50 \mathrm{ppm} \mathrm{HCHO}$ was 85.67, and LOD attained $1.42 \mathrm{ppb}$ at the optimum operating temperature of $100{ }^{\circ} \mathrm{C}$. Atomic-level dispersion not only increases the homogeneity of dispersion, but also reduces the usage of precious metals. Under the cooperation of the two sensitizing properties of precious metals, the sensor has a high response and superior selectivity. The response mechanism is shown in Figure 9. 


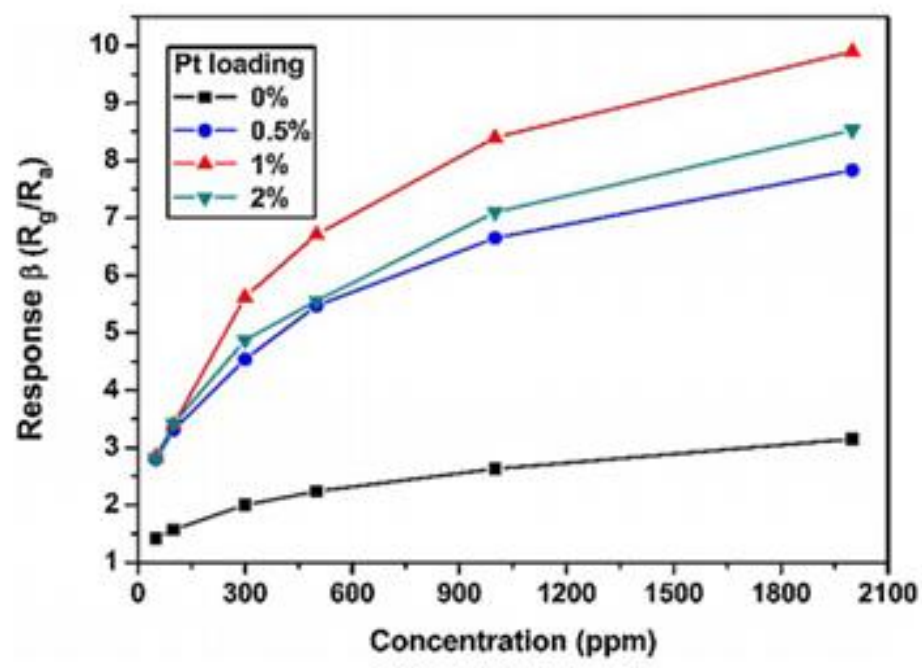

Figure 8. Gas responses of different $\mathrm{Pt}$ doping $\mathrm{NiO}$ based sensors to various concentrations of formaldehyde at optimal operating temperature of $200{ }^{\circ} \mathrm{C}[64]$.

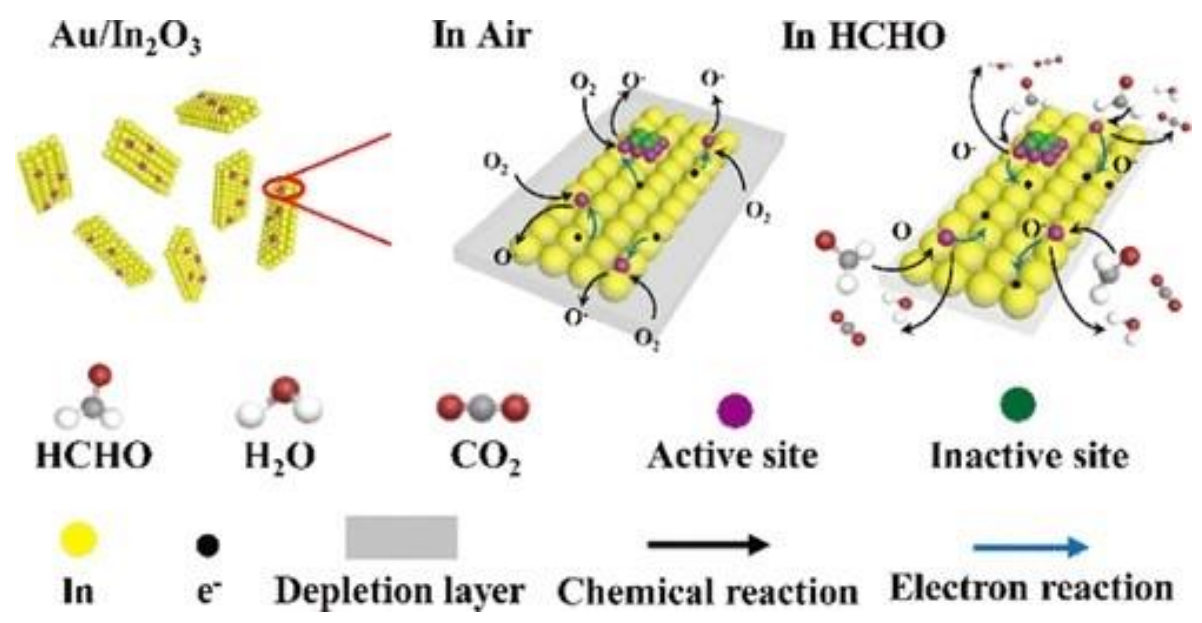

Figure 9. Schematic diagram of the $\mathrm{HCHO}$ sensing mechanism on $\mathrm{Au} / \mathrm{In}_{2} \mathrm{O}_{3}$ [66].

\subsection{Compounding of Semiconductor Oxides}

The composite of oxide semiconductor materials can produce unique interface effects and special properties different from those of its single component, which have a profound impact on the gas-sensing characteristics of gas sensors [67]. In terms of sensitivity, the initial resistance of the composite is much greater than that of the single semiconductor materials. In terms of selectivity, the "synergistic effect" between heterostructures can enhance the selectivity of sensors. In terms of stability, the heterostructure can restrain the regrowth of the crystal grains during annealing to a certain extent, and inhibit the agglomeration of grains when the sensor is used for a long time. In conclusion, heterostructures have shown unique advantages in the field of gas sensitivity.

1. n-n semiconductor oxide composite.

For the composite case of the n-n-type semiconductor, when two different n-type semiconductors contact each other, because of the difference of Fermi energy levels, the carrier will transfer from the semiconductor with a smaller work function to the larger side until it reaches an equilibrium state. Meanwhile, at the contact position, the semiconductor with smaller work function forms a carrier depletion region, and the semiconductor with a larger work function forms a carrier accumulation region [67]. The formation of the carrier 
accumulation region will absorb more oxygen and widen the carrier depletion region, so the initial resistance is increased, and the detection of reducing gas is facilitated.

Abulkosim et al. [68] synthesized $\mathrm{TiO}_{2} @ \mathrm{SnO}_{2}$ nanocomposites using $\mathrm{SnO}_{2}$ powder as substrate by the ALD method. When detecting formaldehyde in the range of sub-ppm, the sensor signal of nanocomposites was higher than that of $\mathrm{SnO}_{2}$, and the optimal measurement temperature was reduced by $50{ }^{\circ} \mathrm{C}$. Sun et al. [69] prepared $\mathrm{ZnO}$ quantum dots modified $\mathrm{SnO}_{2}$ as shown in Figure 10a. The sensor based on $\mathrm{ZnO}$ QDs@SnO ${ }_{2}$ had a faster response speed, and its detection limit reached a ppb level. Wan et al. [70] successfully obtained $\mathrm{In}_{2} \mathrm{O}_{3} @ \mathrm{SnO}_{2}$ core-shell nanofibers. Figure 10b,c exhibit a lower working temperature, and the instantaneous response/recovery time was $3 \mathrm{~s} / 3.6 \mathrm{~s}$, respectively. The excellent gas sensitive parameters of $\mathrm{SnO}_{2}$ nanosheets are mainly due to the huge surface area, the unique electron conversion between the core-shell heterostructures and the synergistic effect of the long electron transport channel of the $\mathrm{SnO}_{2}$ transition layer. Cao et al. [71] modified $\mathrm{WO}_{\mathrm{x}}$ nanoclusters on the thin nano-film of $\operatorname{In}_{2} \mathrm{O}_{3}$ by the impregnation method. The critical detection concentration of the $4 \mathrm{wt} \% \mathrm{WO}_{\mathrm{x}} / \mathrm{In}_{2} \mathrm{O}_{3}$ sensor was $0.1 \mathrm{ppm}$, and the response time was $1 \mathrm{~s}$. The enhanced sensitivity was mainly because of the formation of a heterojunction between $\mathrm{WO}_{\mathrm{x}}$ and $\mathrm{In}_{2} \mathrm{O}_{3}$.

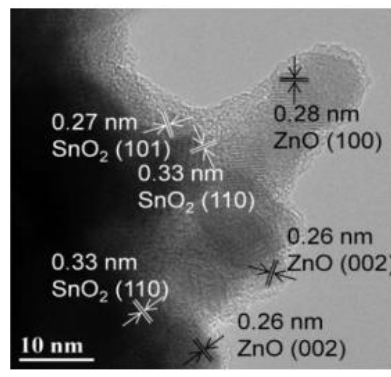

(a)

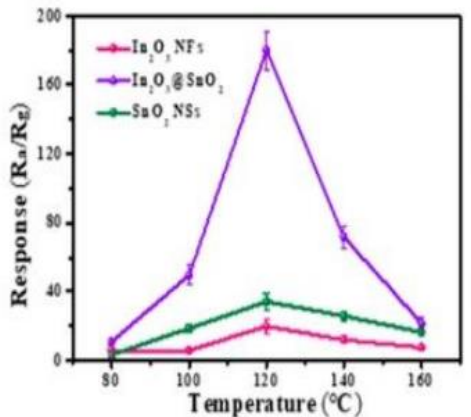

(b)

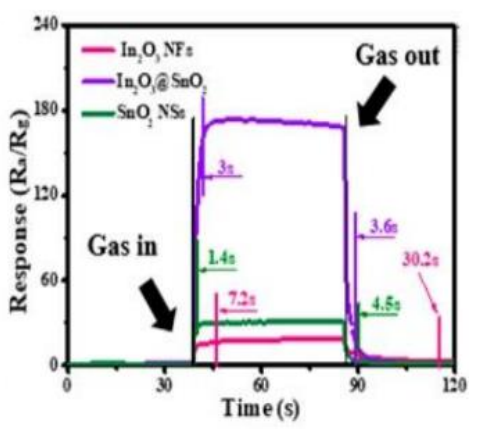

(c)

Figure 10. (a) High-resolution TEM image [69]; (b) response toward $100 \mathrm{ppm}$ of HCHO at operation temperature ranging from 80 to $160{ }^{\circ} \mathrm{C}$; (c) response curves [70].

2. p-n semiconductor oxide composite.

When p-type materials combine with n-type materials, the carriers in two different materials will diffuse to the other side due to the discrepancy in the Fermi energy level [72]. When the Fermi energy level is balanced, an electron depletion zone and a hole depletion zone will be formed at the contact interface, forming a heterojunction and increasing the energy barrier height of carrier conduction between particles.

$\mathrm{Zhu}$ et al. [73] synthesized a $\mathrm{CuO} / \mathrm{SnO}_{2}$ composite for high-performance formaldehyde detection. Compared with the single $\mathrm{CuO}$ NW sensor, the response of composite materials gas sensor with a heterostructure for $\mathrm{HCHO}$ was significantly improved. Figure 11 visually illustrates the gas-sensing mechanism. Zhang et al. [74] obtained $\mathrm{SnO}_{2} @ \mathrm{ZnO}$ nanofibers (NFs) by electrospinning. As a recognized metal oxide with eminent catalytic activity, $\mathrm{NiO}$ produces affluent catalytic active centers in the interface layer. Importantly, the $\mathrm{NiO}$ nanoshell has a highly porous but robust structure, which can improve the utilization of the target gas in the sensing layer. 


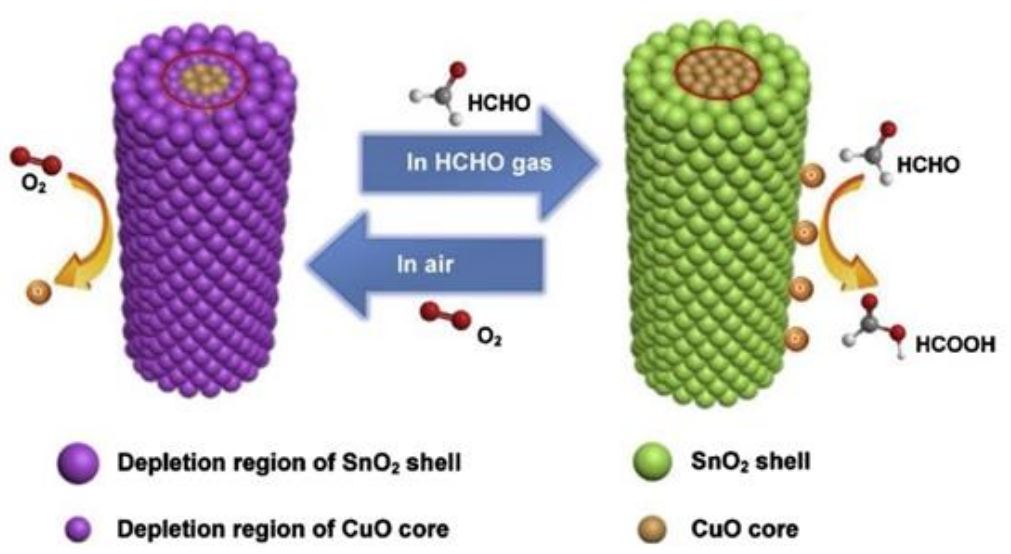

Figure 11. Three-dimensional sensing mechanism diagrams of the carrier distribution in the $\mathrm{p}-\mathrm{CuO} / \mathrm{n}-\mathrm{SnO}_{2}$ core-shell NWs when exposed in air and in $\mathrm{HCHO}$ gas [73].

Table 2. Formaldehyde sensing properties of functional modification of oxide semiconductor gas sensor.

\begin{tabular}{|c|c|c|c|c|c|}
\hline Materials & O.T. $\left({ }^{\circ} \mathrm{C}\right)$ & Response & $\mathrm{T}_{\text {res }} / \mathrm{T}_{\text {rec }}(\mathrm{s})$ & D.L. & Refs \\
\hline $1 \% \mathrm{Co} / \mathrm{In}_{2} \mathrm{O}_{3}$ & 130 & $23.2(10 \mathrm{ppm})$ & $60 / 120$ & $1 \mathrm{ppm}$ & [56] \\
\hline Y-doped $\mathrm{SnO}_{2}$ nanoflowers & 180 & 18 (50 ppm) & $8 / 10$ & $1 \mathrm{ppm}$ & [57] \\
\hline Bi doped $\mathrm{Zn}_{2} \mathrm{SnO}_{4} / \mathrm{SnO}_{2}$ & 180 & $23.2(50 \mathrm{ppm})$ & $16 / 9$ & $10 \mathrm{ppm}$ & [58] \\
\hline 2 at $\%$ Al-doped $\mathrm{ZnO}$ & 320 & 6.8 (50 ppm) & $81 / 21$ & $0.5 \mathrm{ppm}$ & [59] \\
\hline 1\% Pt loaded $\mathrm{NiO}$ & 200 & 9.9 (2000 ppm) & $70 / 102$ & 50 ppm & [64] \\
\hline $5 \% \mathrm{Ag} / \mathrm{In}_{2} \mathrm{O}_{3}$ & 210 & 156.9 (50 ppm) & $57 / 22$ & $10 \mathrm{ppm}$ & [65] \\
\hline Atomically Dispersed $\mathrm{Au} / \mathrm{In}_{2} \mathrm{O}_{3}$ & 100 & 85.67 (50 ppm) & $-/-$ & $1.42 \mathrm{ppb}$ & [66] \\
\hline $\mathrm{TiO}_{2} @ \mathrm{SnO}_{2}$ & 200 & - & $-/-$ & - & [68] \\
\hline ZnO QDs@SnO 2 & 225 & 36.5 (50 ppm) & $9 / 10$ & $\mathrm{ppb}$ & [69] \\
\hline $3 \mathrm{D}$ core- shell $\mathrm{In}_{2} \mathrm{O}_{3} @ S n \mathrm{~S}_{2}$ & 120 & $180(100 \mathrm{ppm})$ & $3 / 3.6$ & $0.01 \mathrm{ppm}$ & [70] \\
\hline $4 \mathrm{wt} \% \mathrm{WO}_{\mathrm{x}} / \operatorname{In}_{2} \mathrm{O}_{3}$ & 170 & $25(100$ ppm $)$ & $1 / 67$ & $0.1 \mathrm{ppm}$ & [71] \\
\hline $\mathrm{CuO} / \mathrm{SnO}_{2}$ & 250 & $2.42(50 \mathrm{ppm})$ & $52 / 80$ & $1.5 \mathrm{ppm}$ & [73] \\
\hline $\mathrm{SnO}_{2}-\mathrm{ZnO} / \mathrm{NiO}$ & 150 & $12.2(200 \mathrm{ppm})$ & $131 / 111$ & - & [74] \\
\hline
\end{tabular}

\section{Development of New Semiconductor Sensitive Materials}

In addition to the commonly used metal oxides as gas-sensing materials, the exploit of new materials for formaldehyde detection is particularly significant. Carbon-based materials (graphene, graphene derivatives and carbon nanotubes) [75], new two-dimensional material and some metal-organic framework (MOF) materials have gradually entered the field of vision of scholars, and they are the major candidates for the preparation of low-power materials.

\subsection{Graphene-Based Formaldehyde Gas Sensor}

Graphene is a typical two-dimensional film with distinctive features of high conductivity, good thermal stability and low electrical noise. When graphene is exposed to air or gas to be measured, the carrier concentration of graphene will change, resulting in a change of resistance [76]. Nevertheless, the practical operation results reveal that the original graphene surface can only adsorb trace gas at room temperature, so its response is limited [77]. Therefore, the use of a variety of semiconductor materials to modify the conductive network of graphene is the main research direction $[78,79]$.

Ye et al. [80] prepared $\mathrm{rGO} / \mathrm{TiO}_{2}$ lamellar thin films on a digital electrode substrate by the spray method for $\mathrm{HCHO}$ sensing applications. The static test results demonstrated that 
the $\mathrm{rGO} / \mathrm{TiO}_{2}$ sensor had the characteristics of high specificity and significant sensitivity. Yin et al. [81] successfully prepared $\mathrm{Sn}_{3} \mathrm{O}_{4} / \mathrm{rGO}$ flowerlike composite and pure $\mathrm{Sn}_{3} \mathrm{O}_{4}$ material by the simple one-step hydrothermal method. The FESME images are shown in Figure 12a,b. From Figure 12c, we can see that by compounding with $\mathrm{Sn}_{3} \mathrm{O}_{4}$, the sensing response of rGO-based sensor clearly improved, and the working temperature was greatly reduced. In particular, the response of $0.75 \mathrm{mg} \mathrm{Sn}{ }_{3} \mathrm{O}_{4} / \mathrm{rGO}$ sensor to $100 \mathrm{ppm} \mathrm{HCHO}$ at $150{ }^{\circ} \mathrm{C}$ was as high as 44 . The enhancement of sensor performance can be attributed to the heterogeneity between $\mathrm{Sn}_{3} \mathrm{O}_{4}$ and $\mathrm{rGO}$.
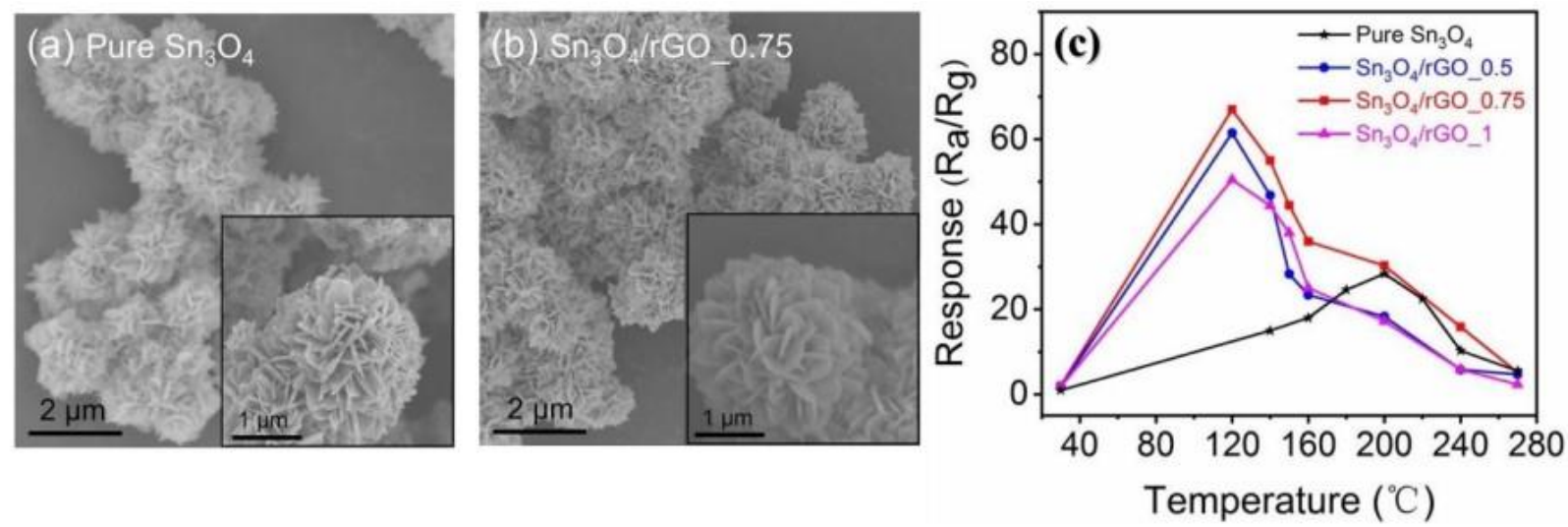

Figure 12. FESEM images of (a) pure $\mathrm{Sn}_{3} \mathrm{O}_{4}$; (b) $\mathrm{Sn}_{3} \mathrm{O}_{4} /$ RGO-0.75 composite; (c) Sensing response of with varying content of rGO sensor toward $100 \mathrm{ppm} \mathrm{HCHO}$ at different operating temperatures [81].

Wan et al. [82] prepared $\mathrm{SnO}_{2} \mathrm{NF} / \mathrm{NSs}$ and then impregnated $\mathrm{GO}$ as a sensitizer. Figure 13a is its O1s spectrum. The sensing performance of formaldehyde was improved by using hierarchical $\mathrm{SnO}_{2} \mathrm{NF} / \mathrm{NSs}$ coated with GO nanofilms. The results show that $1 \%$ content of GO possessed the lowest temperature of $60^{\circ} \mathrm{C}$. Figure 13b,c exhibits the excellent selectivity for formaldehyde, and the minimum detection concentration of nanocomposites was $0.25 \mathrm{ppm}$. The superior gas sensitivity is attributed to the abundance of active sites, a large number of heterojunctions and appropriate electron transfer channels. The $\mathrm{GO} / \mathrm{SnO}_{2}$ nanosheets obtained by Wang et al. [46] had a response of more than 2000 to $100 \mathrm{ppm} \mathrm{HCHO}$ under the working condition of $60^{\circ} \mathrm{C}$. The excellent sensing properties are the result of the cooperative effects of surface porosity, graphene content and the grain size of two-dimensional nanostructures. Figure 14 shows the sensitivity mechanism to formaldehyde gas.

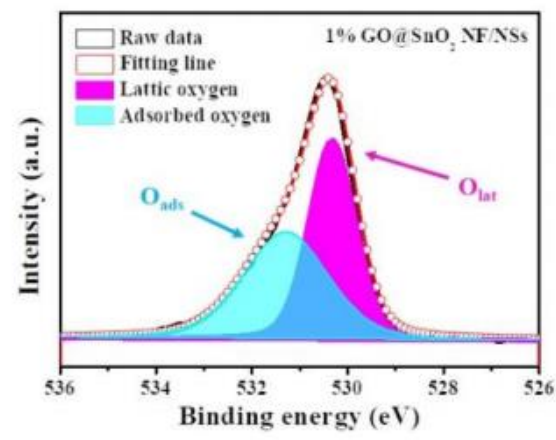

(a)

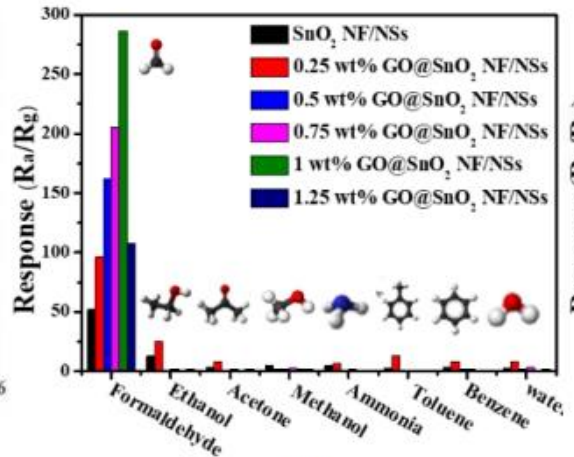

(b)

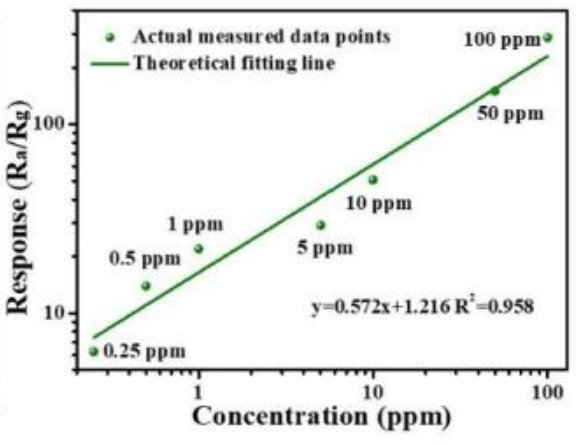

(c)

Figure 13. (a) $\mathrm{O} 1 \mathrm{~s}$ of pure $\mathrm{SnO}_{2} \mathrm{NF} / \mathrm{NSs}$ and $1 \% \mathrm{GO}_{\mathrm{SnO}} \mathrm{NF} / \mathrm{NSs}$ nanocomposites, respectively; (b) responses of the gas sensors to different test gases at their respective optimal operating temperatures; (c) linear approximation of the detection limit with 1\% GO@SnO 2 NF/NSs nanocomposites [82]. 

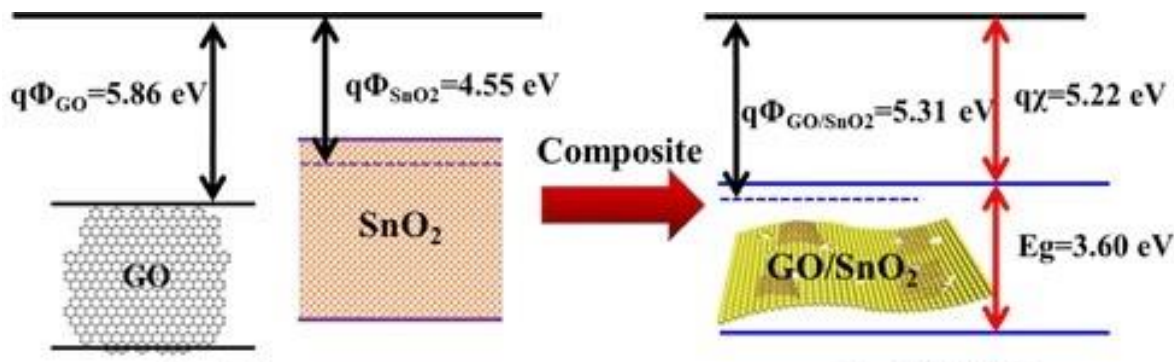

In Air
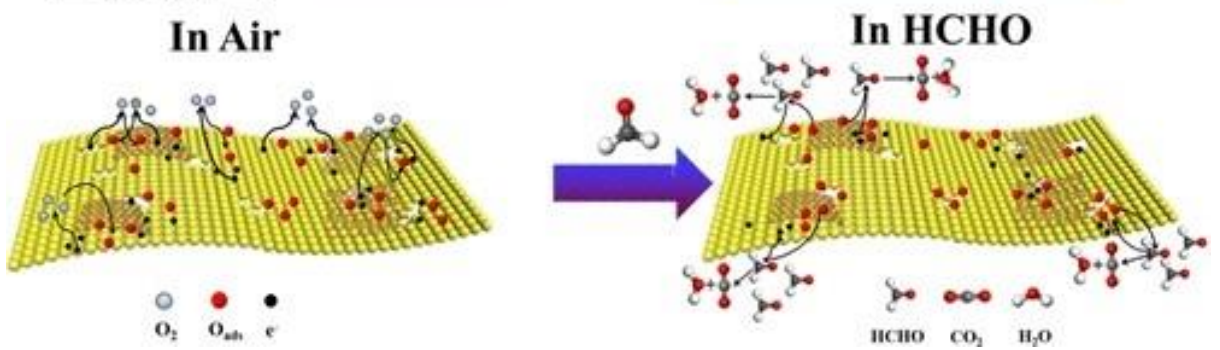

Figure 14. Schematic diagram of the sensing mechanism [46].

Fan et al. [30] assembled graphene nanosheets modified with $\mathrm{ZnO}$ nanoparticles containing dipoles by a simple solution process. ANS greatly promoted the charge transfer between material and formaldehyde molecules, which can be detected at a lower potential barrier. Manna et al. [60] calculated the adsorption properties of $\mathrm{HCHO}$ on graphene oxide (rGO) functionalized with $\mathrm{Pt}, \mathrm{Au}$ and $\mathrm{Ag}$. The quantum simulation results based on DFT show that the adsorption strength of different noble metal composite $\mathrm{rGO}$ to $\mathrm{HCHO}$ varies in the following the order: $\mathrm{rGO}-\mathrm{Pt}_{\mathrm{n}}>\mathrm{rGO}-\mathrm{Au}_{\mathrm{n}}>\mathrm{rGO}-\mathrm{Ag}_{\mathrm{n}}$.

\subsection{Carbon Nanotube-Based Formaldehyde Gas Sensor}

Due to the urgent demand for low-power materials, carbon nanotubes have gradually entered the field of vision of researchers. The response mechanism still relies on the change in conductivity after gas adsorption [83]. The cardinal merit of such sensors is that they can respond at room temperature, which make them the best choice for low-power and portable equipment $[84,85]$. However, thus far, only a few articles based on CNTs sensors for formaldehyde detection have been reported.

Song et al. [86] prepared a micro-scale film bulk acoustic wave formaldehyde sensor by using SWCNTs modified by polyethyleneimine as a sensitive coating. The prepared resonator had a higher operating frequency and was able to monitor the tiny physical changes caused by the absorption of the test gas. We can see in Figure 15a,b that the sensor's monitoring range for formaldehyde was $50-400 \mathrm{ppb}$, and the minimum detection concentration was $24 \mathrm{ppb}$. All the dynamic response processes in Figure $15 \mathrm{c}$ were fully recoverable under different formaldehyde concentrations. Ma et al. [87] prepared a piezoelectric thin film resonator with multi-walled carbon nanotubes as a sensitive layer for the determination of formaldehyde. The experimental results indicate that the sensor can produce a reversible, fast and repeatable response at room temperature. 


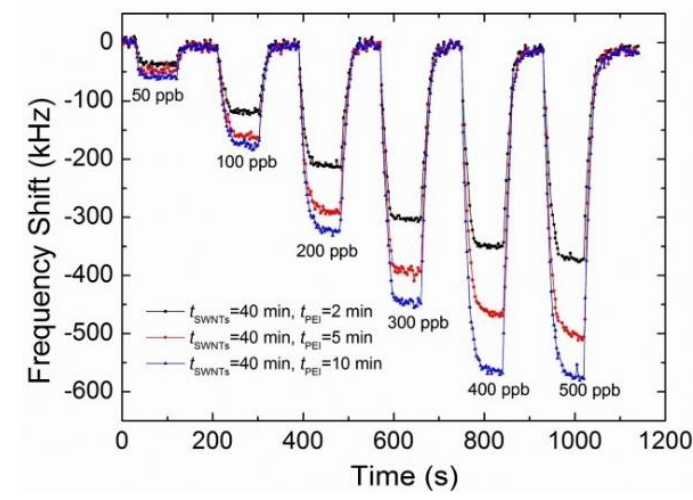

(a)

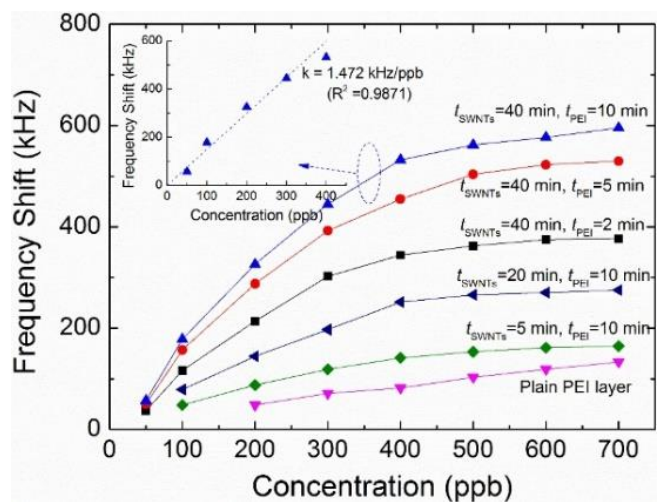

(b)

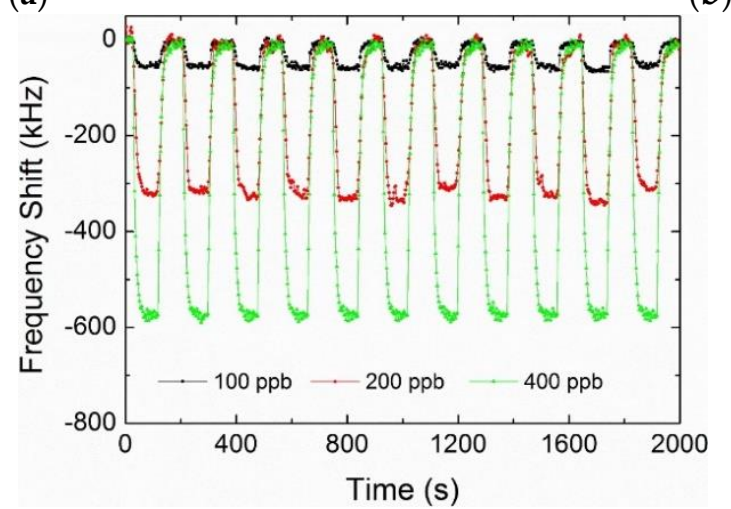

(c)

Figure 15. (a) Dynamic measurement of FBAR sensors in various sensitive layers exposed to formaldehyde pulse at $23{ }^{\circ} \mathrm{C}$ and $40 \% \mathrm{RH}$ with increasing concentration; (b) frequency shift of the FBAR sensors with various sensitive layers as a function of formaldehyde at $23{ }^{\circ} \mathrm{C}$ and $40 \% \mathrm{RH}$. The inset shows the typical linear fitting of the measured results; (c) real-time response towards the sequential pulses of three typical formaldehyde concentrations [86].

\subsection{New Two-Dimensional Material Formaldehyde Gas Sensors}

With the exploration of the use of 2D material graphene in the field of gas sensing, exploring other new 2D crystal materials has been at the forefront of nanomaterials research. Apart from graphene, new 2D materials such as $\mathrm{SnS}_{2}$ [88], $\mathrm{WS}_{2}$ [89], $\mathrm{MoSe}_{2}$ [90], $\mathrm{MoS}_{2}$ [91], $\mathrm{SnSe}_{2}$ [92] and black phosphorus [93] have been explored in depth due to their excellent capability in nano-electronic devices.

Zhang et al. [89] combined $\mathrm{WS}_{2}$ microchips and nano-cubic $\mathrm{Ni}-\mathrm{In}_{2} \mathrm{O}_{3}$ to explore the effect of a ternary complex on formaldehyde properties. Figure 16a compares the variation of five kinds of gas sensors with formaldehyde concentrations. It is obvious from the figure that the response of the $\mathrm{Ni}-\mathrm{In}_{2} \mathrm{O}_{3} / \mathrm{WS}_{2}$ sensor was the largest. Its curve fitting between formaldehyde concentration and the response is described in Figure 16b; the minimum detection value was calculated to be $15 \mathrm{ppb}$. As is evident from Figure $16 \mathrm{c}, \mathrm{d}$, its response was relatively fast, and the selectivity of formaldehyde was better. The reason for the improvement of gas sensitivity parameters lies in the synergistic effect of doping of metal ions and the formation of heterojunctions. N-doped MXene was combined with $\mathrm{TiO}_{2}$ and rGO to form a ternary sensor by Wang et al. [94]; this can overcome the influence of humidity. This paper further expands the application of new two-dimensional materials. However, there is little application of formaldehyde detection based on new two-dimensional materials, and there is still a lot of room for its application in developing new two-dimensional materials for gas-sensing detection. 


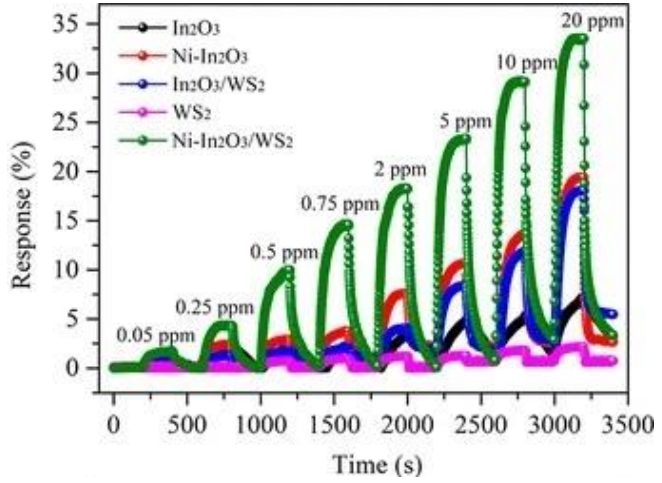

(a)

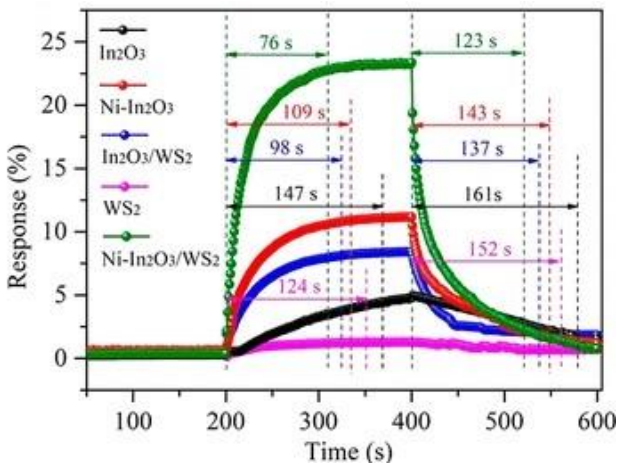

(c)

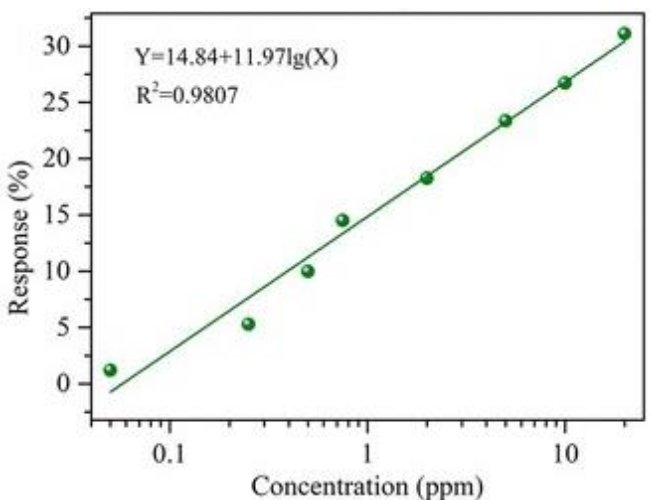

(b)

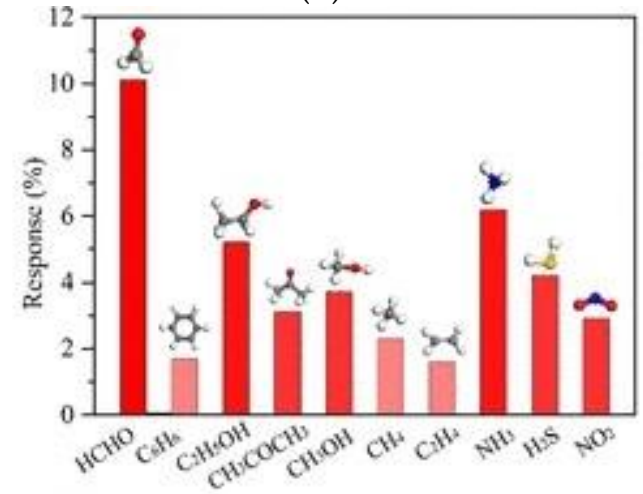

(d)

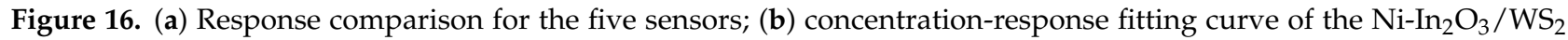
sensor; (c) response and recovery characteristics of the five sensors exposed to $5 \mathrm{ppm}$ formaldehyde; (d) selectivity of the $\mathrm{Ni}-\mathrm{In}_{2} \mathrm{O}_{3} / \mathrm{WS}_{2}$ sensor [89].

\subsection{Application of MOF Materials}

Metal-organic frameworks (MOF) are novel crystalline materials formed by the cooperation of metal ions and organic moieties. Due to their structural adjustability and porous structure, they stand out from various macromolecular materials [95]. Metal-organic frameworks have flexible metal coordination sites and regular porosity, so they can be used as metal ion precursors to realize uniform doping of nanomaterials [96].

Zhu et al. [97] carried out uniform doping of $\mathrm{SnO}_{2}$ by a $\mathrm{Zn}$-containing metal organic framework to monitor HCHO. The structural feature is shown in Figure 17. The rich mesoporous and increased surface area make the response speed faster, and the response value of $15 \mathrm{wt} \% \mathrm{Zn}^{2+}$ doped $\mathrm{SnO}_{2} \mathrm{HNF}$ to $100 \mathrm{ppm} \mathrm{HCHO}$ can reach 25.7. Sun et al. [98] prepared $\mathrm{Co}_{3} \mathrm{O}_{4} / \mathrm{ZnO}$ composites by calcining bimetallic organic frameworks. The gassensing experiments show that the gas sensor parameters, containing response speed, specificity and linearity, of the composite $(\mathrm{Co} / \mathrm{Zn}=4: 1)$ were significantly improved compared with the original $\mathrm{Co}_{3} \mathrm{O}_{4}$ nanomaterials. The main reason for the performance improvement is the ample active sites and high void ratio produced by the pyrolysis of $\mathrm{MOF}$, which is favorable for gas diffusion and surface reaction.

Except for being used as metal ion precursors for uniform doping, metal-organic frame works can also be used as templates to obtain porous oxide nanomaterials by thermal decomposition. Xue et al. [65] prepared $\mathrm{Ag} / \mathrm{In}_{2} \mathrm{O}_{3}$ composites with different contents of Ag by calcining Ag in organic framework (OFS); the results shown in Figure 18 indicate that the gas sensitivity of formaldehyde was excellent at $210^{\circ} \mathrm{C}$ and its response recovery time was significantly shortened. Wang et al. [27] successfully synthesized micron-sized a $\mathrm{SnO}_{2}$ hollow hexagonal prism based on Sn-MOF. The sensor made of this material had 
a high response of 882 at $120^{\circ} \mathrm{C}$, and the response time was as short as $19 \mathrm{~s}$. The large surface area is the chief cause for high gas sensitivity response.
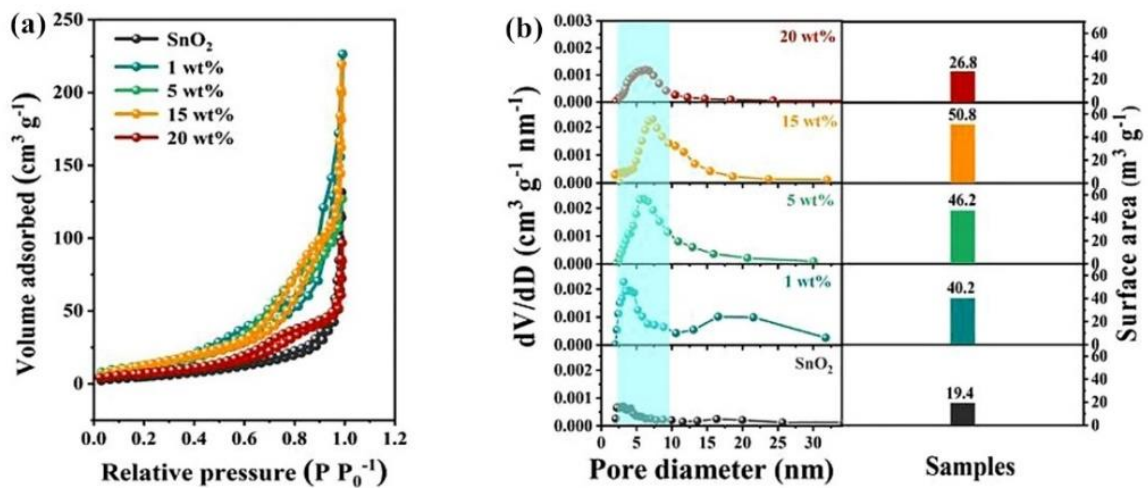

Figure 17. (a) $\mathrm{N}_{2}$ adsorption-desorption isotherm; (b) pore size distribution and surface areas of pristine $\mathrm{SnO}_{2}$ and $\mathrm{ZZS} \mathrm{HNFs} \mathrm{with} \mathrm{different} \mathrm{Zn}^{2+}$ doping amounts [97].
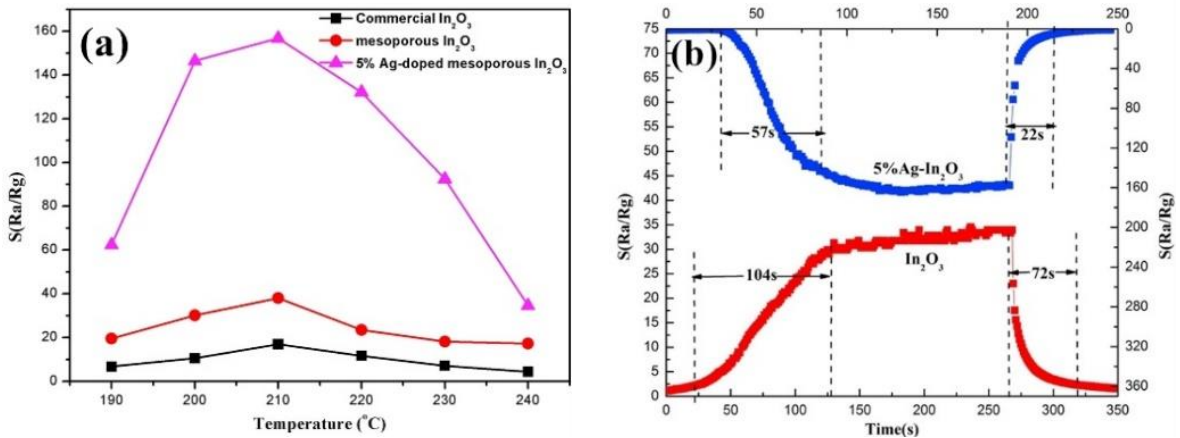

Figure 18. Gas response sensitivities versus operating temperature toward $50 \mathrm{ppm} \mathrm{HCHO} \mathrm{(a);} \mathrm{the}$ response and recovery time (b) of mesoporous $\mathrm{In}_{2} \mathrm{O}_{3}$ and $5 \%$ Ag-loaded mesoporous $\mathrm{In}_{2} \mathrm{O}_{3}$ [65].

\section{Outfield Control}

Working temperature has a unique influence on the conductivity, electron transfer and types of adsorbed oxygen. The sensor property principally depends on working temperature. The metal oxide gas sensor currently studied usually works at $150 \sim 500{ }^{\circ} \mathrm{C}$ [99], because it requires a certain amount of thermal energy to stimulate the gas-sensing reaction, and increase the concentration of free carriers in the sensitive material. However, working at high temperature is a challenge for maintaining stable sensor response and low power consumption; there are certain limitations for the detection of some flammable and explosive gases [100]. To solve above problems, researchers have developed several strategies, including nanostructure optimization, catalyst surface modification, composite nanostructure preparation and outfield control, to create room temperature sensor devices and improve their performance. Light is the most commonly used measure to activate gas sensitive reactions.

\section{Illumination}

The gas-sensing process is essentially an electron transfer process. The band gap structure of oxide is the internal factor affecting the electron transfer process. When the external conditions change, such as illumination or temperature rise, the carriers in semiconductors can become free electrons easily [101]. The improvement of light-induced gas sensitivity is generally caused by the emergence of photogenerated electrons-hole pairs. With the increase of photogenerated electron-hole pairs, the gas adsorption and reaction capacity are enhanced, so light can be used to activate the reaction to better the sensitivity and response speed of the sensor [102]. 
Zhang et al. [103] used a new platform with a high flux resistance measurement capability (HT-RM) to probe the influences of UV-activated $\mathrm{TiO}_{2}$ on the detection performance of formaldehyde. The results show that the UV-activated $\mathrm{TiO}_{2}$ had a higher sensitivity, faster recovery speed and less influence of humidity at $60^{\circ} \mathrm{C}$. Li et al. [104] synthesized a pristine and $\mathrm{Au}$-modified $\mathrm{ZnO} \mathrm{POH}$ s by a simple sacrificial template method. Compared with the pristine $\mathrm{ZnO}$ sensor, the gas-sensitive reaction was enhanced under ultraviolet radiation $(\sim 365 \mathrm{~nm})$. Apart from the high response, the $\mathrm{Au} / \mathrm{ZnO}$ sensor had transcendent linearity, selectivity and reproducibility in the range of 50-800 ppm formaldehyde. Deng et al. [105] prepared mesoporous $\mathrm{WO}_{3}$ and analyzed the gas sensitivity mechanism of sensitive materials to formaldehyde with the help of visible light. The sensing mechanism of visible light-activated gas is presented in Figure 19. Photogenerated electron-hole pairs are generated under light $\left(\mathrm{hv} \rightarrow \mathrm{e}^{-}+\mathrm{h}^{+}\right)$, and the photo-generated holes combine with active oxygen to release oxygen $\left(\mathrm{h}^{+}+\mathrm{O}_{2}^{-} \rightarrow \mathrm{O}_{2}\right)$. As the electrons are released, the carrier depletion zone narrows and the conductivity increases, oxygen in the environment combines with photo-generated electrons to generate additional photo-generated oxygen ions $\left(\mathrm{O}_{2}(\mathrm{~g})+\mathrm{e}^{-} \rightarrow \mathrm{O}_{2}^{-}(\mathrm{hv})\right)$. When encountering formaldehyde, the photo-induced oxygen ions are involved in the redox reaction: $\left(\mathrm{O}_{2}^{-}(\mathrm{hv})+\mathrm{HCHO} \rightarrow \mathrm{CO}_{2}+\mathrm{H}_{2} \mathrm{O}+\mathrm{e}^{-}\right)$; the electron depletion layer becomes narrower and the conductivity increases. The actual redox reaction includes two processes: With the aid of photo-induced oxygen ions, formaldehyde is first converted into formic acid, and then formic acid species is converted into $\mathrm{CO}_{2}$ and $\mathrm{H}_{2} \mathrm{O}$.

$$
\begin{gathered}
\mathrm{O}_{2}^{-}(\mathrm{hv})+\mathrm{HCHO} \rightarrow-\mathrm{O}-\mathrm{HC}-\mathrm{O}-+\mathrm{H}_{2} \mathrm{O}+\mathrm{e}^{-} \\
\mathrm{O}_{2}^{-}(\mathrm{hv})+-\mathrm{O}-\mathrm{HC}-\mathrm{O}-\rightarrow \mathrm{CO}_{2}+\mathrm{H}_{2} \mathrm{O}+\mathrm{e}^{-}
\end{gathered}
$$

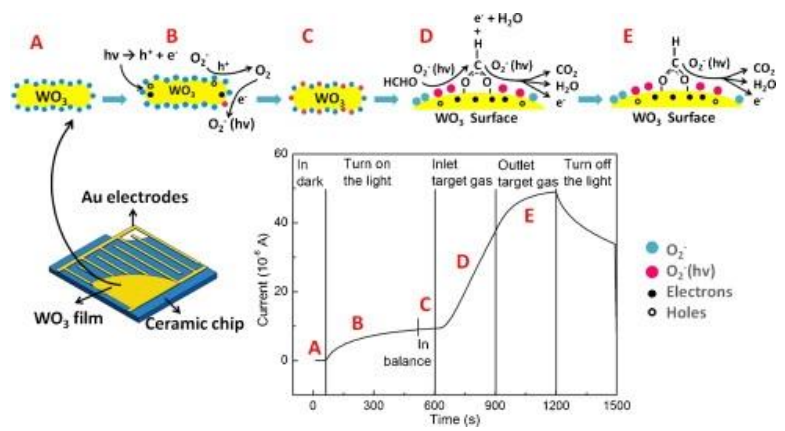

Figure 19. Diagram illustrating the visible-light-activated gas sensing mechanism at room temperature [105].

Visible Light is cheaper and more energy efficient than ultraviolet light. Thus, visible light is more competitive than ultraviolet light in activating gas-sensitive reactions at room temperature.

\section{Construction of Filter Membrane}

Selectivity is a major performance index used to evaluate the utility of sensors. This index can be ameliorated by covering a layer of filter membrane on the outer layer of sensitive materials [106]. When the sensor is put in the mixed gas, only the gas to be measured is allowed to reach the semiconductor oxide surface through the filter membrane, which eliminates the interference gas and improves the selectivity with advantage.

Tian et al. [16] successfully synthesized a core-shell heterostructure by the self-templating method at $70{ }^{\circ} \mathrm{C}$. As shown in Figure 20, ZnO@ZIF-8 nanorods showed different gas responses of VOCs with different molecular sizes. When oxygen passed through the bore diameter of membrane, it became adsorbed oxygen ions on the crystal surface. In VOCs, formaldehyde molecules can easily enter the bore diameter of the filter membrane and 
are oxidized by oxygen species at $300{ }^{\circ} \mathrm{C}$. The order of increasing VOCs diameters was formaldehyde $(2.43 \AA)<$ ammonia $(2.90 \AA)<$ methanol $(3.63 \AA)<$ ethanol $(4.53 \AA)<$ acetone $(4.60 \AA)<$ toluene $(5.25 \AA)$. Due to the restriction of membrane pore size, only some gases were permitted to pass through, so the selectivity for formaldehyde detection has been significantly improved. Kadam [107] used a polyacrylonitrile (PAN) / $\beta$-cyclodextrin ( $\beta$-CD) nanofiber composite membrane to capture atmospheric aerosols and volatile organic compounds (VOC) simultaneously. The results showed that the obtained composite membrane was beneficial to VOC adsorption. The reason for the strong adsorption of formaldehyde is that there are quite a lot of $\mathrm{OH}$ groups on the surface of the composite, and the affinity between the aldehyde groups and the hydroxyl groups is high, which is conducive to the adsorption of $\mathrm{HCHO}$ by $\beta-\mathrm{CD}$.

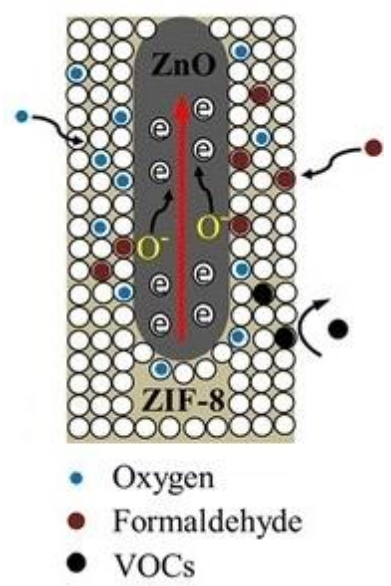

(a)

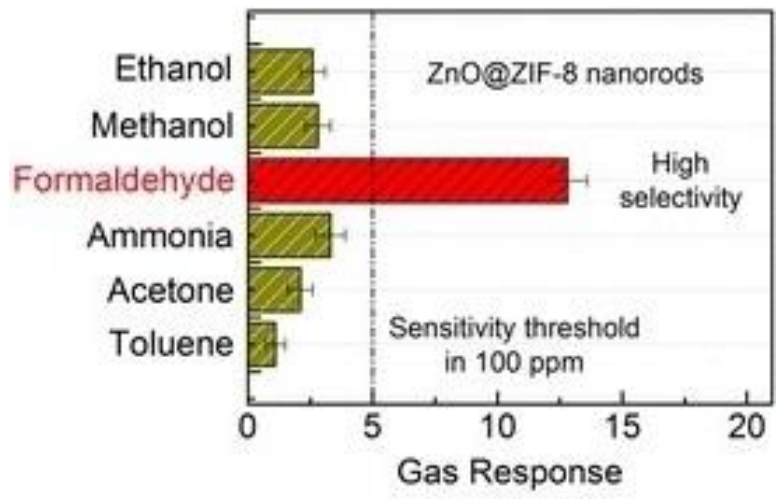

(b)

Figure 20. (a) Schematic illustration of the ZnO@ZIF-8 nanorod sensor with selectivity for different VOCs molecule; (b) gas selectivity to $100 \mathrm{ppm}$ of different VOCs at working temperature of $300{ }^{\circ} \mathrm{C}[16]$.

\section{The Influence of Device Structure on Gas Sensitivity}

In addition to the improvement of the material itself, the device structure of the sensor will also greatly affect the detection parameters. At present, the device structure of the semiconductor gas sensor mainly adopts a two-terminal resistive gas sensor, which mainly adopts a counter electrode or an interdigital electrode to convert the electrical conductivity change of the gas-sensitive material into the change of the device resistance [108]. Resistive device structures mostly use ceramic tube heating sensors. Ceramic materials are inexpensive and resistant to high temperatures, making them suitable for heating metal oxide semiconductor gas sensors. As shown in Figure 21, ceramic tube sensor is mainly composed of ceramic tube, signal electrode and heating electrode. The production process of the sensor is simple, requiring one to evenly coat the prepared sensitive material slurry on the ceramic tube, then put the heating electrode in the ceramic tube, weld it to the hexagonal tube socket, and finally heat and age it. It can be seen that the production cost of the sintered indirectly heated semiconductor gas sensor is low, and the process is simple. However, the thickness of the coated sensitive film is hard to control, and the heat loss is high, which makes the sensor have high power consumption and poor device consistency. 


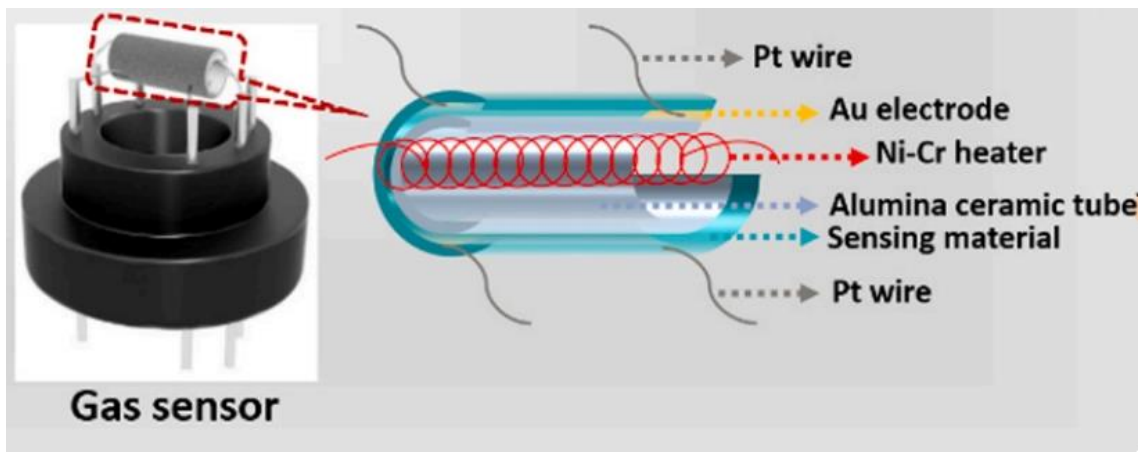

Figure 21. Schematic diagram of sintered indirectly heated gas sensor structure [61].

With the development of micro-nano processing technology, silicon-based micro hot plates developed using micro-electromechanical systems (MEMS) technology are gradually replacing ceramic tubes, further reducing the volume and power consumption of sensors. According to the structure of the supporting film, the micro hot plate can be divided into a diaphragm structure and a cantilever structure. Diaphragm type refers to the support film where the boundary of the active area is in contact with the substrate, while the suspension type uses several cantilever beams as mechanical supports to connect the active area in the middle with the surrounding frame, so that the heating area in the middle is suspended [109]. The temperature distribution of the support film of the two structures is uniform. The former has higher mechanical stability but higher power consumption. While the latter is connected to the surroundings through the support beam, the heat loss of the active area is much smaller, but the mechanical stability is need to be precisely controlled, the production process is also relatively complicated. The top view of the two structures is shown in Figure 22.

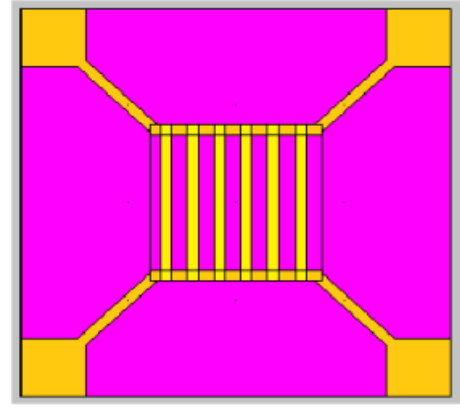

(a)

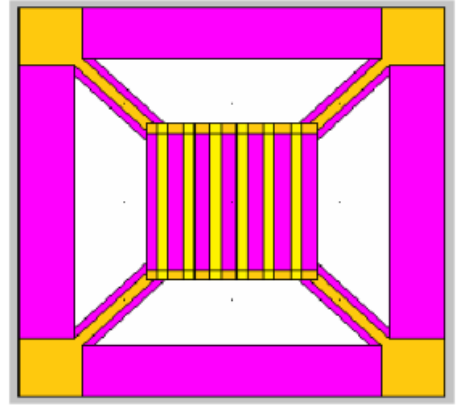

(b)

Figure 22. Top view of micro hot plate structure (a) Diaphragm type; (b) Cantilever type [110].

Flexible sensors have also been studied due to the medical needs. Some low-dimensional nanomaterials and conductive polymer materials can be coated on the substrate of plastic with lower heat-resistant temperatures or even paper by spin-coating, pulling, printing and other ways, to realize the preparation and application of wearable semiconductor gas sensors [111]. The disadvantage is that the key components of the microelectrode device have high impedance, low adhesion and other characteristics, which make it susceptible to failing and falling off. Huang et al. [109] processed the flexible film through a dry plasma etching process to obtain a concave-convex nano-rough structure, and increase the adhesion between the polymer flexible material and the metal layer.

Among the three different sensor devices, electrodes as an important component of the sensor, its main function is to convert the change in the conductivity of the thin film material into an output current or voltage signal, thereby detecting the change in the sensor resistance. In the actual test, since the conductivity of the sensitive material is much lower 
than that of the electrode material, the resistance of the sensitive film deposited on the electrode surface can be ignored. The output resistance of the gas sensor depends mainly on the sensitive film between the interdigital electrodes. The resistance of the gas sensor is not only related to the properties of the sensitive film itself, but also to the size of the electrode [108].

$$
\mathrm{G}=\frac{\mathrm{NW}}{\mathrm{d}}\left(\frac{\mathrm{L}}{\mathrm{N}}-\mathrm{d}\right) \sigma=\left(\frac{\mathrm{L}}{\mathrm{d}}-\mathrm{N}\right) \mathrm{W} \sigma
$$

where $\mathrm{L}$ and $\mathrm{W}$ represent the length and width of the interdigital electrode area, respectively. $\mathrm{N}$ is the number of interdigital electrodes; $\mathrm{d}$ donates the distance between adjacent electrodes; $\sigma$ is the intrinsic conductivity of the film.

Vilanova et al. [112] studied the effect of electrode position and geometry on the gas sensor performance. The simulation results show that when the electrode is placed on the top or the side, the electrode spacing had little effect on the response of the high catalytic activity gas. When the electrode was placed at the bottom of the sensor element, as the electrode spacing decreased, the detection ability of high catalytic activity gas was the same as that of low catalytic activity gas; when the distance was larger, the detection ability of even low catalytic activity gas was the same as that of high catalytic activity gas. Therefore, for our commonly used sensors, when the electrode is placed at the bottom of the sensing element and when the electrode distance is smaller, the wider the electrode, the better the performance. Tamaki et al. [113] used MEMS technology to prepare micro sensors with different electrode spacings. The results show that with the decrease of the electrode spacing, the sensitivity gradually increased. This is mainly because the ratio of the electrode-grain interface resistance to the total resistance of the sensor became larger.

\section{Conclusions}

This paper is divided into three parts: the introductory section, the response mechanisms and the strategy for optimizing gas-sensing performance. We focused on the methods of improving the gas response of semiconductor gas sensors for high-performance formaldehyde detection. There are five ways to ameliorate the gas-sensing property: structure control, doping modification, using new materials, outfield control and the construction of the filter membrane. In addition to optimizing the material itself, the effect of the device structure on gas-sensing properties cannot be ignored.

The control of morphology and structure mainly increases the volume of surfaceactive sites, increasing the porosity and adjusting the grain size to boost the diffusion of gas molecules and surface reaction; doping modification includes metal cation doping, noble metal loading and metal oxide recombination, in which metal ion doping replaces the metal sites in the lattice; carbon-based materials (including graphene, graphene derivatives and CNT) are the first choice for the preparation of low-power materials because of their high conductivity; in addition to carbon-based materials, using light to stimulate the gas reaction is also an important strategy. Apart from carbon-based materials, some new twodimensional materials (such as $\mathrm{PtSe}_{2}, \mathrm{SnS}_{2}, \mathrm{WS}_{2}, \mathrm{MoSe}_{2}, \mathrm{MoS}_{2}$ and black phosphorus) have attracted widespread attention due to their excellent properties in nano-electronic devices, but there is still much room for exploration in the field of gas sensing. MOF materials are also national key research areas currently. They can be used to detect formaldehyde in two ways: one is as a precursor of metal ions for uniform doping, the other is as a template to obtain porous oxide nanomaterials by thermal decomposition. In addition to the parameters of sensitivity, working temperature and response speed, the selectivity of gas detection is also a key factor for consideration. Besides the above improvement measures, the construction of the filter membrane also has a certain effect.

To date, the synthesis of high-performance gas-sensing materials has been accidental. Directional control of material morphology and the realization of gas specific detection are still the main topics of future research. In addition, improving the gas response mechanism is of great significance for the bottom-up preparation of high-performance sensors. 
Author Contributions: Writing—review and editing, Z.Y.; funding acquisition, Z.Y. and F.M.; supervision, Z.Y. and F.M.; investigation, C.Y.; resources, C.Y.; writing-original draft preparation, C.Y.; project administration, F.M.; validation, Z.Y. All authors have read and agreed to the published version of the manuscript.

Funding: This work was supported by the National Key R\&D Program of China (2020YFB2008702), National Natural Science Foundation of China (61973058, 62033002, 61833006 and 62071112), the 111 Project (B16009), the Fundamental Research Funds for the Central Universities in China (N180408018, N2004019 and N2004028), the Liao Ning Revitalization Talents Program (XLYC1807198), the Liaoning Province Natural Science Foundation (2020-KF-11-04), the Hebei Natural Science Foundation (No. F2020501040).

Institutional Review Board Statement: Not applicable.

Informed Consent Statement: Not applicable.

Data Availability Statement: Not applicable.

Conflicts of Interest: The authors declare no conflict of interest.

\section{References}

1. Nielsen, D.G.; Larsen, S.T.; Wolkoff, P. Re-evaluation of the WHO (2010) formaldehyde indoor air quality guideline for cancer risk assessment. Arch. Toxicol. 2017, 91, 35-61. [CrossRef]

2. Pira, E.; Romano, C.; Verga, F.; La Vecchia, C. Mortality from lymphohematopoietic neoplasms and other causes in a cohort of laminated plastic workers exposed to formaldehyde. Cancer Causes Control 2014, 25, 1343-1349. [CrossRef] [PubMed]

3. Bosetti, C.; McLaughlin, J.K.; Tarone, R.E.; Pira, E.; La Vecchia, C. Formaldehyde and cancer risk: A quantitative review of cohort studies through 2006. Ann Oncol. 2008, 19, 29-43. [CrossRef] [PubMed]

4. Bachand, A.M.; Mundt, K.A.; Mundt, D.J.; Montgomery, R.R. Epidemiological studies of formaldehyde exposure and risk of leukemia and nasopharyngeal cancer: A meta-analysis. Crit. Rev. Toxicol. 2010, 40, 85-100. [CrossRef] [PubMed]

5. Fan, H.Z.; Cheng, Y.L.; Gu, C.X.; Zhou, K.W. A novel gas sensor of formaldehyde and ammonia based on cross sensitivity of cataluminescence on nano- $\mathrm{Ti}_{3} \mathrm{SnLa}_{2} \mathrm{O}_{11}$. Sens. Actuators B Chem. 2016, 223, 921-926. [CrossRef]

6. Wei, K.; Ma, L.; Ma, G.P.; Ji, C.D.; Yin, M.Z. A two-step responsive colorimetric probe for fast detection of formaldehyde in weakly acidic environment. Dye. Pigment. 2019, 165, 294-300. [CrossRef]

7. Dong, B.L.; Song, X.Z.; Tang, Y.H.; Lin, W.Y. A rapid and facile fluorimetric method for detecting formaldehyde. Sens. Actuators B Chem. 2016, 222, 325-330. [CrossRef]

8. Zhu, H.B.; She, J.Y.; Zhou, M.L.; Fan, X.D. Rapid and sensitive detection of formaldehyde using portable 2-dimensional gas chromatography equipped with photoionization detectors. Sens. Actuators B Chem. 2019, 283, 182-187. [CrossRef]

9. Shimomura, T.; Itoh, T.; Sumiya, T.; Mizukami, F.; Ono, M. Electrochemical biosensor for the detection of formaldehyde based on enzyme immobilization in mesoporous silica materials. Sens. Actuators B Chem. 2008, 135, 268-275. [CrossRef]

10. Kundu, M.; Bhardwaj, H.; Pandey, M.K.; Krishnan, P.; Kotnala, R.K.; Sumana, G. Development of electrochemical biosensor based on $\mathrm{CNT}-\mathrm{Fe}_{3} \mathrm{O}_{4}$ nanocomposite to determine formaldehyde adulteration in orange juice. J. Food Sci. Technol. 2019, 56, 1829-1840. [CrossRef]

11. Gao, X.G.; Cheng, L.X.; Jiang, W.S.; Li, X.K.; Xing, F. Graphene and its Derivatives-Based Optical Sensors. Front. Chem. 2021, 9, 9. [CrossRef]

12. Ma, N.; Ide, S.; Suematsu, K.; Watanabe, K.; Shimanoe, K. Novel Solid Electrolyte $\mathrm{CO}_{2}$ Gas Sensors Based on c-Axis-Oriented Y-Doped La9.66 $\mathrm{Si}_{5.3} \mathrm{~B}_{0.7} \mathrm{O}_{26.14}$. ACS Appl. Mater. Interfaces 2020, 22, 21515-21520. [CrossRef]

13. Wang, L.; Gao, J.; Xu, J. QCM formaldehyde sensing materials: Design and sensing mechanism. Sens. Actuators B Chem. 2019, 293, 71-82. [CrossRef]

14. Yuan, Z.Y.; Han, E.C.; Meng, F.L.; Zuo, K.Y. Detection and Identification of Volatile Organic Compounds Based on TemperatureModulated ZnO Sensors. IEEE Trans. Instrum. Meas. 2020, 69, 4533-4544. [CrossRef]

15. Li, Y.X.; Chen, N.; Deng, D.Y.; Xing, X.X.; Xiao, X.C.; Wang, Y.D. Formaldehyde detection: $\mathrm{SnO}_{2}$ microspheres for formaldehyde gas sensor with high sensitivity, fast response/recovery and good selectivity. Sens. Actuators B Chem. 2017, 238, 264-273. [CrossRef]

16. Tian, H.L.; Fan, H.Q.; Li, M.M.; Ma, L.T. Zeolitic Imidazolate Framework Coated ZnO Nanorods as Molecular Sieving to Improve Selectivity of Formaldehyde Gas Sensor. ACS Sens. 2016, 1, 243-250. [CrossRef]

17. Lai, X.; Wang, D.; Han, N.; Du, J.; Li, J.; Xing, C.; Chen, Y.; Li, X. Ordered Arrays of Bead-Chain-like $\mathrm{In}_{2} \mathrm{O}_{3} \mathrm{Nanorods}$ and Their Enhanced Sensing Performance for Formaldehyde. Chem. Mater. 2010, 22, 3033-3042. [CrossRef]

18. Choi, S.J.; Chattopadhyay, S.; Kim, J.J.; Kim, S.J.; Tuller, H.L.; Rutledge, G.C.; Kim, I.D. Coaxial electrospinning of WO $\mathrm{W}_{3}$ nanotubes functionalized with bio-inspired Pd catalysts and their superior hydrogen sensing performance. Nanoscale 2016, 8, 9159-9166. [CrossRef] 
19. Lai, X.; Shen, G.; Xue, P.; Yan, B.; Wang, H.; Li, P.; Xia, W.; Fang, J. Ordered mesoporous NiO with thin pore walls and its enhanced sensing performance for formaldehyde. Nanoscale 2015, 7, 4005-4012. [CrossRef]

20. Kim, J.Y.; Choi, N.J.; Park, H.J.; Kim, J.; Lee, D.S.; Song, H. A Hollow Assembly and Its Three-Dimensional Network Formation of Single-Crystalline $\mathrm{Co}_{3} \mathrm{O}_{4}$ Nanoparticles for Ultrasensitive Formaldehyde Gas Sensors. J. Phys. Chem. C 2014, 118, 25994-26002. [CrossRef]

21. Liu, S.; Peng, Y.; Chen, J.J.; Yan, T.; Zhang, Y.N.; Liu, J.; Li, J.H. A new insight into adsorption state and mechanism of adsorbates in porous materials. J. Hazard. Mater. 2020, 382, 121103. [CrossRef] [PubMed]

22. Qin, W.B.; Yuan, Z.Y.; Gao, H.L.; Zhang, R.Z.; Meng, F.L. Perovskite-structured $\mathrm{LaCoO}_{3}$ modified ZnO gas sensor and investigation on its gas sensing mechanism by first principle. Sens. Actuators B Chem. 2021, 341, 130015. [CrossRef]

23. Ji, H.C.; Zeng, W.; Li, Y.Q. Gas sensing mechanisms of metal oxide semiconductors: A focus review. Nanoscale 2019, 11, 2664-22684. [CrossRef]

24. Park, H.J.; Kim, J.; Choi, N.J.; Song, H.; Lee, D.S. Nonstoichiometric Co-rich $\mathrm{ZnCo}_{2} \mathrm{O}_{4}$ Hollow Nanospheres for High Performance Formaldehyde Detection at ppb Levels. ACS Appl. Mater. Interfaces 2016, 8, 3233-3240. [CrossRef]

25. Yamazoe, N. New approaches for improving semiconductor gas sensor. Sens. Actuators B Chem. 1991, 5, 7-19. [CrossRef]

26. Liang, Q.H.; Qu, X.J.; Bai, N.; Chen, H.; Zou, X.X. Alkali metal-incorporated spinel oxide nanofibers enable high performance detection of formaldehyde at ppb level. J. Hazard. Mater. 2020, 400, 123301. [CrossRef]

27. Wang, B.J.; Ma, S.Y.; Pei, S.T.; Xu, X.L.; Cao, P.F. High specific surface area $\mathrm{SnO}_{2}$ prepared by calcining Sn-MOFs and their formaldehyde-sensing characteristics. Sens. Actuators B Chem. 2020, 321, 128560. [CrossRef]

28. Zhang, X.S.; Gu, R.Q.; Zhao, J.L.; Jin, G.X.; Zhao, M.K.; Xue, Y.L. Effects of Particle Size on the Gas Sensitivity and Catalytic Activity of $\mathrm{In}_{2} \mathrm{O}_{3}$. J. Mater. Eng. Perform. 2015, 24, 3815-3819. [CrossRef]

29. Han, M.A.; Kim, H.J.; Lee, H.C.; Park, J.S.; Lee, H.N. Effects of porosity and particle size on the gas sensing properties of SnO 2 films. Appl. Surf. Sci. 2019, 481, 133-137. [CrossRef]

30. Fan, J.C.; Li, H.; Hu, H.Y.; Niu, Y.; Hao, R.T.; Umar, A. An insight into improvement of room temperature formaldehyde sensitivity for graphene-based gas sensors. Microchem. J. 2021, 160, 105607. [CrossRef]

31. Tian, S.Q.; Ding, X.H.; Zeng, D.W.; Zhang, S.P.; Xie, C.S. Pore-size-dependent sensing property of hierarchical $\mathrm{SnO}_{2} \mathrm{mesoporous}$ microfibers as formaldehyde sensors. Sens. Actuators B Chem. 2013, 186, 640-647. [CrossRef]

32. Wang, B.R.; Wang, R.Z.; Ming, B.M.; Sun, J.B.; Liu, L.Y.; Zhang, Y.F. Surface state effect on gas sensitivity in nano-hierarchical tin oxide. Ceram. Int. 2020, 46, 26871-26879. [CrossRef]

33. Umar, A.; Ibrahim, A.A.; Kumar, R.; Albargi, H.; Zeng, W.; Alhmami, M.A.M.; Alsaiari, M.A.; Baskoutas, S. Gas sensor device for high-performance ethanol sensing using $\alpha-\mathrm{MnO}_{2}$ nanoparticles. Mater. Lett. 2021, 286, 129232. [CrossRef]

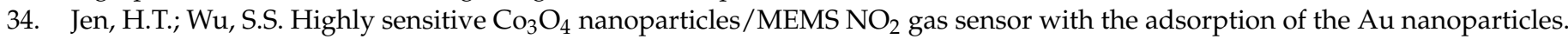
Sens. Actuators B Chem. 2020, 329, 129201.

35. Yu, Z.Y.; Zhang, L.; Wang, X.Y.; He, D.; Suo, H.; Zhao, C. Fabrication of ZnO/Carbon Quantum Dots Composite Sensor for Detecting NO Gas. Sensors 2020, 20, 4961. [CrossRef] [PubMed]

36. Bouchikhi, B.; Chludziński, T.; Saidi, T.; Smulko, J.; El Bari, N.; Wen, H.; Ionescu, R. Formaldehyde detection with chemical gas sensors based on $\mathrm{WO}_{3}$ nanowires decorated with metal nanoparticles under dark conditions and UV light irradiation. Sens. Actuators B Chem. 2020, 320, 128331. [CrossRef]

37. Zhang, P.; Zhang, L.X.; Xu, H.; Xing, Y.; Chen, J.J. Ultrathin $\mathrm{CeO}_{2}$ nanosheets as bifunctional sensing materials for humidity and formaldehyde detection. Rare Met. 2020, 40, 1614-1621. [CrossRef]

38. Liu, Y.L.; Zeng, W. Facile synthesis of 3D flower-like $\mathrm{MoO}_{3}$ and its gas sensor application. J. Mater. Sci. Mater. Electron. 2016, 27, 12996-13001. [CrossRef]

39. Meng, F.L.; Hou, N.N.; Ge, S.; Sun, B.; Jin, Z. Flower-like hierarchical structures consisting of porous single-crystalline ZnO nanosheets and their gas sensing properties to volatile organic compounds (VOCs). J. Alloys Compd. 2015, 626, 124-130. [CrossRef]

40. Yuan, Z.Y.; Zuo, K.Y.; Meng, F.L.; Ma, Z.W.; Xu, W.X.; Dong, H. Microscale analysis and gas sensing characteristics based on $\mathrm{SnO}_{2}$ hollow spheres. Microelectron. Eng. 2020, 231, 111372. [CrossRef]

41. Imran, M.; Motta, N.; Shafiei, M. Electrospun one-dimensional nanostructures: A new horizon for gas sensing materials. Beilstein J. Nanotechnol. 2018, 9, 2128-2170. [CrossRef]

42. Xu, K.; Zeng, D.W.; Tian, S.Q.; Zhang, S.P.; Xie, C.S. Hierarchical porous $\mathrm{SnO}_{2}$ micro-rods topologically transferred from tin oxalate for fast response sensors to trace formaldehyde. Sens. Actuators B Chem. 2014, 190, 585-592. [CrossRef]

43. Zhao, R.J.; Zhang, X.; Peng, S.J.; Hong, P.; Zou, T. Shaddock peels as bio-templates synthesis of Cd-doped $\mathrm{SnO}_{2}$ nanofibers: A high performance formaldehyde sensing material. J. Alloys Compd. 2020, 813, 152170. [CrossRef]

44. Qin, S.W.; Tang, P.G.; Feng, Y.J.; Li, D.Q. Novel ultrathin mesoporous $\mathrm{ZnO}-\mathrm{SnO}_{2} \mathrm{n}-\mathrm{n}$ heterojunction nanosheets with high sensitivity to ethanol. Sens. Actuators B Chem. 2020, 309, 127801. [CrossRef]

45. Chen, H.T.; Li, C.L.; Zhang, X.G.; Yang, W. ZnO nanoplates with abundant porosity for significant formaldehyde-sensing. Mater. Lett. 2020, 260, 126982. [CrossRef]

46. Wang, D.; Tian, L.; Li, H.J.; Wan, K.C.; Yu, X. Mesoporous Ultrathin $\mathrm{SnO}_{2}$ Nanosheets in Situ Modified by Graphene Oxide for Extraordinary Formaldehyde Detection at Low Temperatures. ACS Appl. Mater. Interfaces 2019, 11, 12808-12818. [CrossRef]

47. Meng, F.L.; Qi, T.Y.; Zhang, J.J.; Zhu, H.M.; Yuan, Z.Y. $\mathrm{MoS}_{2}$-templated porous hollow $\mathrm{MoO}_{3}$ microspheres for highly selective ammonia sensing via a Lewis acid-base interaction. IEEE Trans. Ind. Electron. 2021, online ahead of print. [CrossRef] 
48. Park, H.J.; Hong, S.Y.; Chun, D.H.; Kang, S.W.; Park, J.C.; Lee, D.S. A highly susceptive mesoporous hematite microcube architecture for sustainable P-type formaldehyde gas sensors. Sens. Actuators B Chem. 2019, 287, 437-444. [CrossRef]

49. Hu, J.C.; Wang, H.P.; Chen, M.P.; Zhang, Y.M.; Zhao, X.B. Constructing hierarchical $\mathrm{SnO}_{2}$ nanoflowers for enhanced formaldehyde sensing performances. Mater. Lett. 2020, 263, 126843. [CrossRef]

50. Tao, Z.H.; Li, Y.W.; Zhang, B.; Sun, G.; Xiao, M. Synthesis of urchin-like $\mathrm{In}_{2} \mathrm{O}_{3}$ hollow spheres for selective and quantitative detection of formaldehyde. Sens. Actuators B Chem. 2019, 298, 126889. [CrossRef]

51. Zi, B.Y.; Chen, M.P.; Zhang, Y.M.; Rong, Q.; Hu, J.C. Morphology-dependent formaldehyde detection of porous copper oxide hierarchical microspheres at near-room temperature. Microporous Mesoporous Mater. 2020, 302, 126889. [CrossRef]

52. Zhang, R.; Liu, X.P.; Zhou, T.T.; Zhang, T. Controllable construction of multishelled p-type cuprous oxide with enhanced formaldehyde sensing. J. Colloid Interface Sci. 2019, 535, 58-65. [CrossRef] [PubMed]

53. Han, Z.J.; Qi, Y.; Yang, Z.Y.; Han, H.C.; Jiang, Y.Y. Recent advances and perspectives on constructing metal oxide semiconductor gas sensing materials for efficient formaldehyde detection. J. Mater. Chem. C 2020, 8, 13169-13188. [CrossRef]

54. Dong, C.; Liu, X.; Han, B.; Deng, S.; Xiao, X.; Wang, Y. Nonaqueous synthesis of Ag-functionalized $\operatorname{In}_{2} \mathrm{O}_{3} / \mathrm{ZnO} \mathrm{nanocomposites}$ for highly sensitive formaldehyde sensor. Sens. Actuators B Chem. 2016, 224, 193-200. [CrossRef]

55. Esrafili, M.D.; Dinparast, L. The selective adsorption of formaldehyde and methanol over Al- or Si-decorated graphene oxide: A DFT study. J. Mol. Graph. Modell. 2018, 80, 25-31. [CrossRef]

56. Wang, Z.H.; Hou, C.L.; De, Q.M.; Gu, F.B.; Han, D.M. One-Step Synthesis of Co-Doped $\operatorname{In}_{2} \mathrm{O}_{3}$ Nanorods for High Response of Formaldehyde Sensor at Low Temperature. ACS Sens. 2018, 3, 468-475. [CrossRef]

57. Zhu, K.M.; Ma, S.Y.; Tie, Y.; Zhang, Q.X.; Wang, W.Q. Highly sensitive formaldehyde gas sensors based on Y-doped SnO 2 hierarchical flower-shaped nanostructures. J. Alloys Compd. 2019, 792, 938-944. [CrossRef]

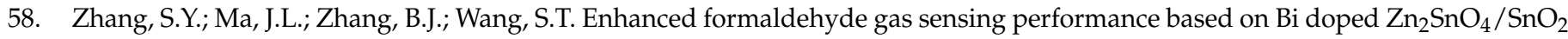
porous nanospheres. J. Alloys Compd. 2020, 828, 154408. [CrossRef]

59. Khojier, K. Preparation and investigation of Al-doped $\mathrm{ZnO}$ thin films as a formaldehyde sensor with extremely low detection limit and considering the effect of RH. Mater. Sci. Semicond. Process. 2021, 121, 105283. [CrossRef]

60. Manna, B.; Chakrabarti, I.; Guha, P.K. First Principles Study of Noble Metal (Single Atom and Cluster) Decorated Reduced Graphene Oxide for Efficient Formaldehyde Adsorption. IEEE Sens. J. 2021, 21, 2544-2551. [CrossRef]

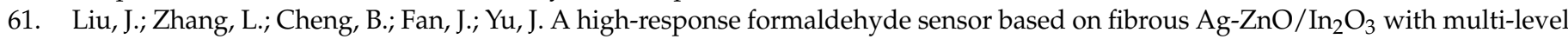
heterojunctions. J. Hazard. Mater. 2021, 413, 125352. [CrossRef]

62. Zhou, S.; Chen, M.; Lu, Q.; Zhang, Y.; Zhang, J.; Li, B.; Wei, H.; Hu, J.; Wang, H.; Liu, Q. Ag Nanoparticles Sensitized In ${ }_{2} \mathrm{O}_{3}$ Nanograin for the Ultrasensitive HCHO Detection at Room Temperature. Nanoscale Res. Lett. 2019, 14, 365. [CrossRef] [PubMed]

63. Mun, Y.; Park, S.; An, S.; Lee, C.; Kim, H.W. $\mathrm{NO}_{2}$ gas sensing properties of Au-functionalized porous ZnO nanosheets enhanced by UV irradiation. Ceram. Int. 2013, 39, 8615-8622. [CrossRef]

64. Dong, C.J.; Li, Q.; Chen, G.; Xiao, X.C.; Wang, Y.D. Enhanced formaldehyde sensing performance of 3D hierarchical porous structure Pt-functionalized $\mathrm{NiO}$ via a facile solution combustion synthesis. Sens. Actuators B Chem. 2015, 220, 171-179. [CrossRef]

65. Xue, Y.Y.; Wang, J.L.; Li, S.N.; Jiang, Y.C.; Hu, M.C.; Zhai, Q.G. Mesoporous Ag/ $\operatorname{In}_{2} \mathrm{O}_{3}$ composite derived from indium organic framework as high performance formaldehyde sensor. J. Solid State Chem. 2017, 251, 170-175. [CrossRef]

66. Gu, F.B.; Di, M.Y.; Han, D.M.; Hong, S.; Wang, Z.H. Atomically Dispersed Au on $\operatorname{In}_{2} \mathrm{O}_{3}$ Nanosheets for Highly Sensitive and Selective Detection of Formaldehyde. ACS Sens. 2020, 5, 2611-2619. [CrossRef]

67. Yao, Y.G.; Yuan, J.H.; Chen, X.X.; Tan, L.M.; Zhao, W.J. In situ construction and sensing mechanism of $\mathrm{TiO}_{2}-\mathrm{WO}_{3}$ composite coatings based on the semiconductor heterojunctions. J. Mater. Res. Technol. 2019, 8, 3580-3588. [CrossRef]

68. Nasriddinov, A.; Rumyantseva, M.; Marikutsa, A.; Gaskov, A.; Lee, J.-H.; Kim, J.-H.; Kim, J.-Y.; Kim, S.S.; Kim, H.W. Sub-ppm Formaldehyde Detection by n-n $\mathrm{TiO}_{2} @ \mathrm{SnO}_{2}$ Nanocomposites. Sensors 2019, 19, 3182. [CrossRef]

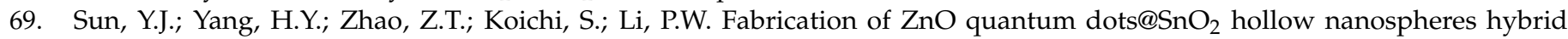
hierarchical structures for effectively detecting formaldehyde. Sens. Actuators B Chem. 2020, 318, 128222. [CrossRef]

70. Wan, K.C.; Wang, D.; Wang, F.; Li, H.J.; Xu, J.C. Hierarchical $\mathrm{In}_{2} \mathrm{O}_{3} @ \mathrm{SnO}_{2}$ Core-Shell Nanofiber for High Efficiency Formaldehyde Detection. ACS Appl. Mater. Interfaces 2019, 11, 45214-45225. [CrossRef]

71. Cao, Y.Y.; He, Y.; Zou, X.X.; Li, G.D. Tungsten oxide clusters decorated ultrathin $\mathrm{In}_{2} \mathrm{O}_{3}$ nanosheets for selective detecting formaldehyde. Sens. Actuators B Chem. 2017, 252, 232-238. [CrossRef]

72. Zhang, H.; Chen, W.G.; Li, Y.Q.; Song, Z.H.; Zeng, W.; Tang, S.R. Hierarchical heterostructures of nanosheet-assembled NiOmodified $\mathrm{ZnO}$ microflowers for high performance acetylene detection. Ceram. Int. 2020, 46, 3574-3581. [CrossRef]

73. Zhu, L.Y.; Yuan, K.P.; Yang, J.G.; Ma, H.P.; Wang, T.; Ji, X.M. Fabrication of heterostructured p-CuO/n-SnO 2 core-shell nanowires for enhanced sensitive and selective formaldehyde detection. Sens. Actuators B Chem. 2019, 290, 233-241. [CrossRef]

74. Zhang, R.; Zhou, T.T.; Zhang, T. Functionalization of Hybrid $1 \mathrm{D} \mathrm{SnO}_{2}-\mathrm{ZnO}$ Nanofibers for Formaldehyde Detection. Adv. Mater. Interfaces 2018, 5, 1800967. [CrossRef]

75. Pargoletti, E.; Cappelletti, G. Breakthroughs in the Design of Novel Carbon-Based Metal Oxides Nanocomposites for VOCs Gas Sensing. Nanomaterials 2020, 10, 1845. [CrossRef]

76. Kumar, V.; Vikrant, K.; Kim, K.H. Use of graphene-based structures as platforms for the trace-level detection of gaseous formaldehyde and insights into their superior sensing potentials. TrAC Trends Anal. Chem. 2019, 121, 115694. [CrossRef] 
77. Zhang, D.Z.; Liu, J.J.; Jiang, C.X.; Liu, A.M.; Xia, B.K. Quantitative detection of formaldehyde and ammonia gas via metal oxide-modified graphene-based sensor array combining with neural network model. Sens. Actuators B Chem. 2017, $240,55-65$. [CrossRef]

78. Wei, Q.; Sun, J.; Song, P.; Yang, Z.X.; Wang, Q. Synthesis of reduced graphene oxide $/ \mathrm{SnO}_{2}$ nanosheets / Au nanoparticles ternary composites with enhanced formaldehyde sensing performance. Phys. E Low Dimens. Syst. Nanostruct. 2020, 118, 113953. [CrossRef]

79. Ashraf, M.A.; Liu, Z.; Peng, W.; Parsaee, Z. Design, preparation and evaluation of a high performance sensor for formaldehyde based on a novel hybride nonocomposite $\mathrm{ZnWO}_{3} / \mathrm{rGO}$. Anal. Chim. Acta 2019, 1051, 120-128. [CrossRef]

80. Ye, Z.B.; Tai, H.L.; Xie, T.; Yuan, Z.; Liu, C.H.; Jiang, Y.D. Room temperature formaldehyde sensor with enhanced performance based on reduced graphene oxide/titanium dioxide. Sens. Actuators B Chem. 2016, 223, 149-156. [CrossRef]

81. Yin, F.F.; Li, Y.; Yue, W.J.; Gao, S.; Zhang, C.W.; Chen, Z.X. $\mathrm{Sn}_{3} \mathrm{O}_{4} / \mathrm{rGO}$ heterostructure as a material for formaldehyde gas sensor with a wide detecting range and low operating temperature. Sens. Actuators B Chem. 2020, 312, 127954. [CrossRef]

82. Wan, K.C.; Yang, J.L.; Wang, D.; Wang, X.Y. Graphene Oxide@3D Hierarchical $\mathrm{SnO}_{2}$ Nanofiber/Nanosheets Nanocomposites for Highly Sensitive and Low-Temperature Formaldehyde Detection. Molecules 2019, 25, 35. [CrossRef]

83. Han, M.; Kim, J.K.; Lee, J.; An, H.K.; Yun, J.P. Room-Temperature Hydrogen-Gas Sensor Based on Carbon Nanotube Yarn. J. Nanosci. Nanotechnol. 2020, 20, 4011-4014. [CrossRef]

84. Inoue, S.; Tomita, Y.; Matsumura, Y. Effect of thickness of carbon nanotube films on enhancement of sensor response. Chem. Phys. Lett. 2019, 734, 136730. [CrossRef]

85. Vu, T.D.; Cong, T.N.; Huu, B.L.; Duc, C.N.; Huu, L.N. Surface-Modified Carbon Nanotubes for Enhanced Ammonia Gas Sensitivity at Room Temperature. J. Nanosci. Nanotechnol. 2019, 19, 7447-7451. [CrossRef]

86. Song, S.R.; Chen, D.; Wang, H.F.; Guo, Q.Q.; Wang, W.; Wu, M.Z. Film bulk acoustic formaldehyde sensor with polyethyleneiminemodified single-wall carbon nanotubes as sensitive layer. Sens. Actuators B Chem. 2018, 266, 204-212. [CrossRef]

87. Ma, J.L.; Wang, S.T.; Chen, D.; Wang, W.; Zhang, Z.; Song, S.R. ZnO piezoelectric film resonator modified with multi-walled carbon nanotubes/polyethyleneimine bilayer for the detection of trace formaldehyde. Appl. Phys. A 2017, 124, 56. [CrossRef]

88. Yan, W.-J.; Lv, C.; Zhang, D.; Chen, Y.; Zhang, L.; Coileáin, C.Ó.; Wang, Z.; Jiang, Z.; Hung, K.-M.; Chang, C.-R.; et al. Enhanced $\mathrm{NO}_{2}$ Sensitivity in Schottky-Contacted n-Type $\mathrm{SnS}_{2}$ Gas Sensors. ACS Appl. Mater. Interfaces 2020, 12, 26746-26754. [CrossRef] [PubMed]

89. Zhang, D.Z.; Fan, X.; Hao, X.F.; Dong, G.K. Nanoheterostructure Construction and DFT Study of Ni-Doped $\mathrm{In}_{2} \mathrm{O}_{3} \mathrm{Nanocubes}_{2} \mathrm{WS}_{2}$ Hexagon Nanosheets for Formaldehyde Sensing at Room Temperature. ACS Appl. Mater. Interfaces 2020, 12, 11979-11989. [CrossRef]

90. Singh, S.; Singh, R.C.; Sharma, S. Room temperature ammonia sensing using $\mathrm{MoSe}_{2}$ nanostructures. Mater. Today 2020, 28 , 11-13. [CrossRef]

91. Yuan, Z.Y.; Liu, Y.; Zhang, J.J.; Meng, F.L.; Zhang, H. Rose-Like $\mathrm{MoO}_{3} / \mathrm{MoS}_{2} / \mathrm{rGO}$ Low-Temperature Ammonia Sensors Based on Multigas Detection Methods. IEEE Trans. Instrum. Meas. 2021, 70, 9506019. [CrossRef]

92. Chen, M.; Li, Z.; Li, W.; Shan, C.; Li, W.; Li, K.; Gu, G.; Feng, Y.; Zhong, G.; Wei, L.; et al. Large-scale synthesis of single-crystalline self-standing $\mathrm{SnSe}_{2}$ nanoplate arrays for wearable gas sensors. Nanotechnology 2018, 29, 455501. [CrossRef]

93. Wu, Y.; Yuan, W.; Xu, M.; Bai, S.; Chen, Y.; Tang, Z.; Wang, C.; Yang, Y.; Zhang, X.; Yuan, Y.; et al. Two-dimensional black phosphorus: Properties, fabrication and application for flexible supercapacitors. Chem. Eng. J. 2021, 412, 128744. [CrossRef]

94. Wang, Y.H.; Zhou, Y.; Wang, Y.J. Humidity activated ionic-conduction formaldehyde sensing of reduced graphene oxide decorated nitrogen-doped MXene/titanium dioxide composite film. Sens. Actuators B Chem. 2020, 323, 128695. [CrossRef]

95. Zheng, Y.; Zheng, S.S.; Xue, H.G.; Pang, H. Metal-Organic Frameworks/Graphene-Based Materials: Preparations and Applications. Adv. Funct. Mater. 2018, 28, 1804950. [CrossRef]

96. Xu, X.Y.; Yan, B. Eu(iii)-functionalized ZnO@MOF heterostructures: Integration of pre-concentration and efficient charge transfer for the fabrication of a ppb-level sensing platform for volatile aldehyde gases in vehicles. J. Mater. Chem. 2017, 5, 2215-2223. [CrossRef]

97. Zhu, L.; Wang, J.N.; Liu, J.W.; Nasir, M.S.; Zhu, J.W.; Li, S.S. Smart formaldehyde detection enabled by metal organic frameworkderived doped electrospun hollow nanofibers. Sens. Actuators B Chem. 2021, 326, 128819. [CrossRef]

98. Sun, J.; Sun, L.; Bai, S.; Fu, H.; Guo, J.; Feng, Y.; Luo, R.; Li, D.; Chen, A. Pyrolyzing Co/Zn bimetallic organic framework-derived doped electrospun hollow nanofibers. Sens. Actuators B Chem. 2019, 285, 291-301. [CrossRef]

99. Wang, J.; Hu, C.Y.; Xia, Y.; Zhang, B. Mesoporous ZnO nanosheets with rich surface oxygen vacancies for UV-activated methane gas sensing at room temperature. Sens. Actuators B Chem. 2021, 333, 129547. [CrossRef]

100. Zhang, C.; Boudiba, A.; De Marco, P.; Snyders, R.; Olivier, M.G.; Debliquy, M. Room temperature responses of visible-light illuminated $\mathrm{WO}_{3}$ sensors to $\mathrm{NO}_{2}$ in sub-ppm range. Sens. Actuators B Chem. 2013, 181, 395-401. [CrossRef]

101. Tian, X.; Yang, X.; Yang, F.; Qi, T.J. A visible-light activated gas sensor based on perylenediimide-sensitized $\mathrm{SnO}_{2}$ for $\mathrm{NO}_{2}$ detection at room temperature. Colloids Surf. A 2019, 578, 123621. [CrossRef]

102. Wang, J.; Shen, H.; Xia, Y.; Komarneni, S. Light-activated room-temperature gas sensors based on metal oxide nanostructures: A review on recent advances. Ceram. Int. 2020, 47, 7353-7368. [CrossRef]

103. Zhang, S.P.; Lei, T.; Li, D.; Zhang, G.Z.; Xie, C.S. UV light activation of $\mathrm{TiO}_{2}$ for sensing formaldehyde: How to be sensitive, recovering fast, and humidity less sensitive. Sens. Actuators B Chem. 2014, 202, 964-970. [CrossRef] 
104. Li, Y.; Jin, H.; Sun, G.; Zhang, B.; Luo, N.; Lin, L.; Bala, H.; Cao, J.; Zhang, Z.; Wang, Y. Synthesis of novel porous ZnO octahedrons and their improved UV-light activated formaldehyde-sensing performance by Au decoration. Phys. E Low Dimens. Syst. Nanostruct. 2019, 106, 40-44. [CrossRef]

105. Deng, L.B.; Ding, X.H.; Zeng, D.W.; Tian, S.Q.; Li, H.Y.; Xie, C.S. Visible-light activate mesoporous $\mathrm{WO}_{3}$ sensors with enhanced formaldehyde-sensing property at room temperature. Sens. Actuators B Chem. 2012, 163, 260-266. [CrossRef]

106. Nian, P.; Li, Y.J.; Zhang, X.; Cao, Y.; Liu, H.O.; Zhang, X.F. ZnO Nanorod-Induced Heteroepitaxial Growth of SOD Type Co-Based Zeolitic Imidazolate Framework Membranes for $\mathrm{H}_{2}$ Separation. ACS Appl. Mater. Interfaces 2018, 10, 4151-4160. [CrossRef] [PubMed]

107. Kadam, V.; Truong, Y.B.; Easton, C.; Mukherjee, S.; Wang, L.; Padhye, R.; Kyratzis, I.L. Electrospun Polyacrylonitrile/ $\beta$-Cyclodextrin Composite Membranes for Simultaneous Air Filtration and Adsorption of Volatile Organic Compounds. ACS Appl. Nano Mater. 2018, 1, 4268-4277. [CrossRef]

108. Lee, S.P. Electrodes for Semiconductor Gas Sensors. Sensors 2017, 4, 683. [CrossRef]

109. Huang, Z.L.; Zeng, Q.; Hui, Y.; Qin, S.J.; Wu, T.Z. Fast Polymerization of Polydopamine Based on Titanium Dioxide for High-Performance Flexible Electrodes. ACS Appl. Mater. Interfaces 2020, 12, 14495-14506. [CrossRef] [PubMed]

110. Niu, G.; He, L.; Yang, Z.; Zhao, C.; Gong, H.; He, W.; Wang, F. A Micro-Hotplate for MEMS Based Gas Sensor. In Proceedings of the 2018 19th International Conference on Electronic Packaging Technology (ICEPT), Shanghai, China, 8-11 August 2018; pp. 749-752.

111. Han, S.T.; Peng, H.; Sun, Q.; Venkatesh, S.; Chung, K.S.; Lau, S.C.; Zhou, Y.; Roy, V.A.L. An Overview of the Development of Flexible Sensors. Adv. Mater. 2017, 29, 1700375. [CrossRef] [PubMed]

112. Vilanava, X.; Llobet, E.; Brezmes, J.; Calderer, J.; Correig, X. Numerical simulation of the electrode geometry and position effects on semiconductor gas sensor response. Sens. Actuators B Chem. 1998, 48, 425-431. [CrossRef]

113. Tamaki, J.; Miyaji, A.; Makinodan, J.; Ogura, S.; Konishi, S. Effect of micro-gap electrode on detection of dilute $\mathrm{NO}_{2}$ using $\mathrm{WO}_{3}$ thin film microsensors. Sens. Actuators B Chem. 2005, 108, 202-206. [CrossRef] 